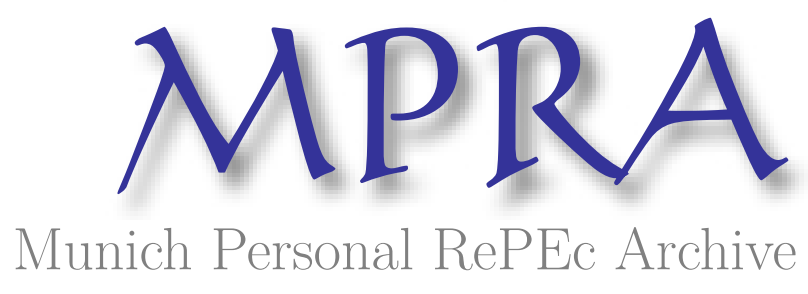

\title{
Specific Human Capital and Wait Unemployment
}

Herz, Benedikt

February 2017

Online at https://mpra.ub.uni-muenchen.de/76777/

MPRA Paper No. 76777, posted 14 Feb 2017 18:42 UTC 


\title{
Specific Human Capital and Wait Unemployment
}

\author{
Benedikt Herz*
}

February 2017

First version: October 2014

\begin{abstract}
A displaced worker might rationally prefer to wait through a long spell of unemployment instead of seeking employment at a lower wage in a job he is not trained for. I evaluate this trade-off using micro-data on displaced workers. To achieve identification, I exploit that the more a worker invested in occupation-specific human capital the more costly it is for him to switch occupations and the higher is therefore his incentive to wait. I find that between $9 \%$ and $18 \%$ of total unemployment in the United States can be attributed to wait unemployment.
\end{abstract}

JEL-Classification: E24, J61, J62

Keywords: wait unemployment, rest unemployment, specific human capital, worker mobility, mismatch, displaced workers

*European Commission, 1049 Brussels, Belgium (e-mail: benedikt.herz@gmail.edu). I gratefully acknowledge the hospitality of the Department of Economics at New York University and the University of Warwick as well as financial support from the Spanish Ministry of Science and Innovation (Grant BES2009-027251). I also thank Thijs van Rens, Michael McMahon, Albrecht Glitz, Nezih Guner, Vasco Carvalho, Regis Barnichon, Yanos Zylberberg, and an anonymous referee for valuable advice. The opinions expressed in this publication do not necessarily reflect the opinion of the European Commission. 


\section{Introduction}

Labor is not a homogeneous commodity. The Dictionary of Occupational Titles (DOT) published by the U.S. Department of Labor distinguishes among over 12000 occupations. A majority of these occupations require highly specialized training. According to the DOT, the majority of the workforce in the United States is employed in occupations that require more than a year of vocational preparation specific to that occupation. The U.S. labor market is therefore not a single market where one homogeneous type of labor is traded. Instead, it is more appropriate to think of it as being composed of many skill-specific sub-markets or "islands."

Two distinct but potentially complementary mechanisms of how this heterogeneity can give rise to unemployment have been discussed in the literature. On the one hand, search models - in particular models based on Lucas Jr. and Prescott (1974) - assume that moving across sub-markets is time-intensive. In a heterogeneous labor market that is subject to reallocation shocks, unemployment can therefore arise as a consequence of workers looking for new job opportunities.

An alternative view is that a worker who has been displaced is still attached to his pre-displacement job and tries to find reemployment in a similar position (e.g., Shimer, 2007; Alvarez and Shimer, 2011). A potential consequence is what I refer to as wait unemployment: instead of searching on different islands, workers prefer to wait and sit through long unemployment spells hoping that their old job reappears. Whereas search is a theory of former steel workers looking for positions as nurses, the latter is a theory of former steel workers waiting for their former plant to reopen (Shimer, 2007).

The objective of this paper is to test and quantify the concept of wait unemployment and to assess its importance for aggregate unemployment in the United States. Because human capital is only partially transferable across jobs, a displaced worker prefers to find a new position that is as similar as possible to the job he worked in before. If such a position is not readily available the worker faces a trade-off. On the one hand, he can work in a different job. Because human capital is usually compensated by a higher wage, this will go along with a wage-loss that I refer to as a mobility cost. The alternative is to evade this mobility cost and to instead sit through a long spell of unemployment and wait until a similar job becomes available.

I quantify this trade-off using micro-data on displaced workers in the United States. To achieve identification I make use of a difference-in-differences strategy in the spirit of Rajan and Zingales (1998) that relies on two sources of variation. Firstly, I exploit that the extent of specific human capital a worker invested in varies by occupation. For example, an industrial engineer spent many more years preparing for his job than a waiter. I operationalize this by using data on the specific vocational preparation (SVP) required to work in a given occupation provided by the Dictionary of Occupational Titles. A displaced worker who leaves an occupation with high SVP gives up a substantial stock of human capital and suffers a wage-loss. The higher the SVP of the 


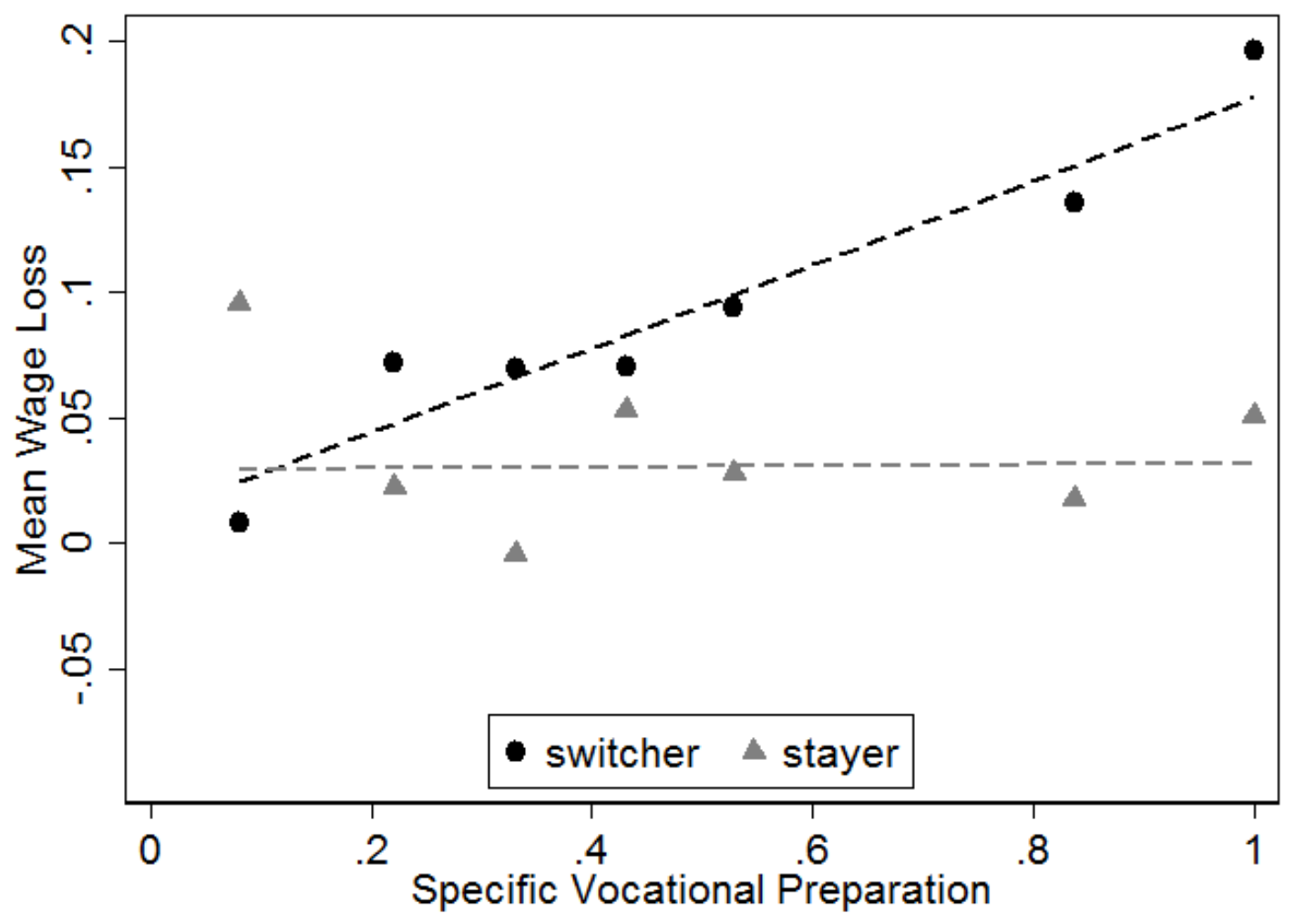

Figure 1: The relationship between the wage-loss after displacement and specific vocational preparation (SVP) is shown. I differentiate between workers who report to have switched occupations after displacement (black circles) and workers who stayed in the same occupation (gray triangles). The lines visualize weighted linear fits. It is apparent that the cost of switching occupations - what I refer to as mobility cost - is strongly increasing in SVP. The fact that a similar relation is not observable for occupation stayers is reassuring evidence that the driving force is indeed the loss of occupation-specific human capital of switchers. Data on SVP comes from the the revised fourth edition of the Dictionary of Occupational Titles (1991). Data on wage-losses comes from the Current Population Survey Displaced Workers Supplement (CPS-DWS).

occupation a worker is trained in, the higher is therefore the mobility cost this worker is facing when switching occupations. One contribution of this paper is to document that this relation is strongly confirmed in the data, see Figure 1.

Secondly, I exploit geographic variation by using local labor market information from the U.S. Census. Local labor markets differ regarding their thickness. In a thick labor market it will be relatively easier to find a job that matches a worker's skill-set, even when highly specialized; mobility cost are therefore less likely to be binding. I use two alternative measures to operationalize market thickness. My first measure is the size of the local labor force. If workers and firms are heterogeneous in their skill endowments and requirements, an increase in trading partners increases the probability that a worker can find a vacancy that matches his skills. My second measure is the industrial diversity of the local labor market. In a diverse market, employment (and vacancies) are evenly distributed across many industries. Since employment of most occupations spans many 
different industries, in a diverse market it is more likely that at any given time there is a vacancy matching a given worker skill.

Based on these two sources of variation, I construct the following test. I use data from the Current Population Survey Displaced Worker Supplement (CPS-DWS) that contains information on completed unemployment spells of workers displaced between 1983 and 2012 in the U.S. labor market. I examine the sample of displaced workers who managed to find a job in the same occupation they worked in before. I then compare the unemployment spells of more and less specialized workers in thin and thick local labor markets. If wait unemployment matters, workers with more specific training should have relatively longer spells in thin markets where mobility costs are likely to be binding. In thick markets, on the other hand, the difference should be smaller or even non-existent.

My empirical results are in line with this hypothesis. For example, based on my regression results, I find that in the thick New York metropolitan area labor market a industrial engineer who finds reemployment as a industrial engineer goes through an unemployment spell that is about 3 weeks longer than a waiter who finds reemployment as a waiter. On the other hand, in the relatively thin Bakersfield, CA metropolitan area a industrial engineer sits through an unemployment spell that is almost 9 weeks longer than that of a waiter to find a job in his old occupation. The differential unemployment spell is therefore about 6 weeks.

My interpretation of this finding is that in Bakersfield, CA it is relatively more difficult to find reemployment in the same occupation and therefore to transfer human capital to the next job. Since waiters only made small investments in occupation-specific training they prefer switching occupations to going through a long unemployment spell. Industrial engineers, on the other hand, have substantial occupation-specific training and would suffer high wage-losses when switching occupations. They are therefore willing to go trough relatively longer unemployment spells in order to find reemployment as industrial engineers.

I find that the occupation switching behavior of workers is consistent with this interpretation. While $60 \%$ of industrial engineers find reemployment as industrial engineers, only $30 \%$ of waiters stay in their occupation in the New York metropolitan area and only 19\% in the thin Bakersfield, CA labor market. Moreover, based on a difference-in-difference-in-differences approach, I document that long unemployment spells can only be found for occupation stayers but not for occupation switchers. Since my estimation strategy allows me to control for occupation- (and local-labor market) fixed effects, I can exclude that my results are driven by any inherent differences between occupations.

Finally, I push the exercise further and use a worker's specific vocational preparation as an instrument in a (two-sample) two-stage least squares (TS2SLS) regression to obtain direct estimates of how mobility cost affect unemployment duration. I find that in thin labor markets even small mobility costs can lead to very substantial 
increases in unemployment duration.

My results have important macroeconomic implications. Using a back-of-the-envelope calculation I find that there would be between $9 \%$ and 18\% less unemployment in the United States if human capital would be transferable and switching occupations would not entail any mobility cost. Moreover, I argue that my findings might offer important insights for the design of an optimal unemployment insurance system.

\subsection{Related Literature}

The idea that specificity of human capital can lead to long spells of wait unemployment is not new. To the best of my knowledge, Murphy and Topel (1987) are the first to mention this channel explicitly. In particular, they note that it is compatible with the observation that increased unemployed tends to go along with reduced inter-sectoral mobility. This finding is strong evidence against sectoral-shift theories of unemployment as, for example, proposed by Lilien (1982).

One strand of literature formalizes this idea in models where workers can undergo spells of "rest unemployment." Jovanovic (1987), Hamilton (1988), King (1990), Gouge and King (1997), and more recently Alvarez and Shimer (2008) extend the basic island model by Lucas Jr. and Prescott (1974). When a worker is subject to an adverse shocks that lowers his wage he might rationally prefer not to work and to wait for better times instead of undertaking a costly search for a better industry or occupation on another "island." A sharp difference to my framework is that in models of rest unemployment wages always fully adjust and clear markets. Rest unemployment exists because workers have a utility from resting that might dominate working at the current market wage. In my framework, on the other hand, the extent of wage adjustments is a critical factor in driving unemployment. Workers are never voluntarily unemployed but they are queuing in order to put their human capital to optimal use.

There is an older literature on transitional or wait unemployment that most resembles the concept of unemployment I have in mind. The basic idea is that due to rigidities there are good and bad jobs that pay workers of equal ability different wages. A fraction of workers rationally decide to queue and go through long unemployment spells in order to get one of the highly paid jobs. This creates unemployment. Recently Alvarez and Shimer (2008), based on ideas by Summers et al. (1986), claim that wage dispersion caused by unions leads to substantial unemployment. In a classical paper Harris and Todaro (1970) identify wage differentials between rural and urban jobs as a source of wait unemployment. Wait unemployment in my framework is different inasmuch that workers are not queuing in order to seize rents but because they want to preserve valuable specific human capital.

I also contribute to a big literature that empirically studies the specificity of human capital, particularly 
by analyzing earnings losses of displaced workers. Early papers in this literature tried to estimate the cost of losing firm-specific capital (Abraham and Farber, 1987; Altonji and Shakotko, 1987; Kletzer, 1998; Topel, 1991). Neal (1995) and Parent (2000) analyzed the costs of changing industry after displacement. More recently, there is growing evidence that human capital is mostly occupation- and not industry-specific (Kambourov and Manovskii, 2009). I contribute to this literature by showing that the cost of switching differs substantially across occupations; leaving an occupation is more costly for workers who underwent lengthy and highly specific occupational training (e.g., physicians) than for workers in occupations that makes use of mostly general skills (e.g., waiters).

This paper also builds on a literature that explores the link between local labor market thickness, the quality of job matches, and worker mobility. Helsley and Strange (1990) were the first to formalize the idea that, if workers and firms (vacancies) are heterogeneous in their skill endowments and requirements, an increase in trading partners increases the probability that a worker can find a vacancy that matches his skills. Thicker labor markets therefore imply better job match quality and higher labor productivity. A consequence of this result is that local labor market thickness also affects worker mobility. For example, both Wheeler (2008) and Bleakley and Lin (2012) find evidence that workers early in their careers residing in thick labor markets are more likely to change industries and occupations, presumably because they experiment with different types of work to find out what job matches their skills best. More experienced workers, on the other hand, try to evade the loss of specific human capital. Since the likelihood that a similar job is available in a thick market is relatively high, these workers are therefore less likely to switch occupation and industry in thick local labor markets. My findings are consistent with this evidence. The present paper adds to this literature by using the insight that the likelihood to find re-employment in a similar job is increasing in local labor market thickness in the estimation strategy

Finally, this paper contributes to the literature on labor market mismatch and structural unemployment. This research has attracted increasing interest in recent times due to high and persistent unemployment rates during and after the Great Recession of 2008 and because of claims that "structural factors" are behind this development (Kocherlakota, 2010). Sahin et al. (2014) combine unemployment records with data on posted vacancies to calculate mismatch unemployment in the U.S. labor market. They find that mismatch across industries and occupations explains at most one-third of the increase of unemployment in the Great Recession while geographic mismatch does not play a role. Barnichon and Figura (2011) use CPS data to explore the effect of mismatch on matching efficiency. They find that lower matching efficiency due to mismatch can have significant detrimental effect for unemployment in recessions. Herz and van Rens (2015) push the analysis a step further by identifying several potential driving forces of mismatch unemployment and estimate their relative 
importance. This paper is complementary to this literature since I quantify evidence of how on very specific channel - workers "waiting" for reemployment since they made specific investments ex-ante - contributes to mismatch unemployment.

The remainder of this article proceeds as follows. In Section 2, I describe the different data sources that I use for estimation. I discuss the basic estimation framework in Section 3. In Section 4, I estimate the relation between SVP and mobility cost. Estimates of wait unemployment are presented in Section 5. I discuss the macroeconomic implications of wait unemployment in Section 6. Firstly, using a "back-of-the-envelope" calculation I show the importance of wait unemployment for aggregate unemployment in the United States. Secondly, I discuss potential implications for the design of an optimal unemployment insurance system. Section 7 concludes. A stylized model that formally shows the relation between market thickness and wait unemployment is presented in the appendix.

\section{Data and Measurement}

\subsection{Displaced Workers}

My primary data set is the Current Population Displaced Workers Supplement (CPS-DWS) that has been widely used for research on earnings-losses of displaced workers. ${ }^{1}$ The CPS-DWS was part of the CPS in January 1988, February 1994, 1996, 1998, and 2000, and in January 2002, 2004, 2006, 2008, 2010, and 2012. CPS respondents are asked whether they lost a job in the three years prior to the survey date (five years in 1988). Those individuals who report having lost a job are part of the CPS-DWS and asked follow-up questions. This ex-post design is the comparative advantage of the CPS-DWS because it allows the researcher to observe completed unemployment spells and provides information about a worker's old and new job. In particular, job-losers are asked about both their pre- and post-displacement weekly earnings, their pre- and post-displacement occupation, ${ }^{2}$ reasons for displacement, and about the length of their initial unemployment spell. ${ }^{3}$ I refer the reader to the data appendix A.2 for more information about the CPS-DWS and the exact sample that I use in this study.

\footnotetext{
${ }^{1}$ Some of the classic papers are Topel (1990), Gibbons and Katz (1991), Carrington (1993), Neal (1995), Farber et al. (1993), and Farber et al. (1997).

${ }^{2}$ Occupation codes used in the CPS underwent several changes between 1988 and 2012. I therefore construct 384 time-consistent occupation codes by using the conversion tables provided by Meyer and Osborne (2005).

${ }^{3}$ The exact wording of the question is "After that job ended, how many weeks went by before you started working again at another job?" That is, this is not exactly an unemployment spell but includes workers who are inactive. So the best fit between my empirical framework and the data that is available is obtained when one thinks of unemployed workers in the framework as comprising both inactive and unemployed workers.
} 
Table 1: Specific Vocational Preparation

\begin{tabular}{llll}
\hline \hline & SVP & Time required & Example \\
\hline 1 & $0.1 \%$ & Short demonstration only & refuse and recycable materials collectors \\
2 & $8.0 \%$ & Anything beyond short demonstration $\leq 1$ month & janitors, bartenders \\
3 & $22.1 \%$ & Over 1 month up to and including 3 months & laundry workers, waiter/waitress \\
4 & $33.0 \%$ & Over 3 months up to and including 6 months & general office clerks, receptionist \\
5 & $43.1 \%$ & Over 6 months up to and including 1 year & welders and cutters, bank tellers \\
6 & $52.9 \%$ & Over 1 year up to and including 2 years & chemical technicians, insurance sales \\
7 & $83.7 \%$ & Over 2 years up to and including 4 years & registered nurses, lectricians \\
8 & $99.9 \%$ & Over 4 years up to and including 10 years & chemical engineers, lawyers, physicians \\
9 & $100.0 \%$ & Over 10 years & judges \\
\hline \hline
\end{tabular}

Notes: Definitions of the various levels of specific vocational preparation from the 1991 revised fourth edition of the Dictionary of Occupational Titles are reported. The first column shows the original (ordinal) variable. The second column shows the transformed (cardinal) variable. The latter was generated by constructing an empirical cumulative distribution function of SVP based on the 1995 basic monthly CPS data. For example, 52.9\% of the workforce in 1995 were employed in occupations requiring at most 2 years of specific vocational preparation. Note that there is only one occupation in the highest category (judges) and one in the lowest category (refuse and recycable materials collectors).

\subsection{Specific Vocational Preparation}

My identification strategy requires a measure of the occupation-specific human capital a worker invested in. I operationalize this by drawing on the "specific vocational preparation" (SVP) required to work in a given occupation provided by the revised fourth edition of the Dictionary of Occupational Titles (DOT) published by the U.S. Department of Labor in 1991. SVP is defined as "the amount of lapsed time required by a typical worker to learn the techniques, acquire the information, and develop the facility needed for average performance in a specific job-worker situation." ${ }^{4}$ The variable that I use in this paper can be interpreted as the share of the employed workforce that works in occupations with equal or smaller required specific vocational preparation. See Table 1 for a description of the variable. I refer the reader to the data appendix for more information on the construction of the variable.

\subsection{Market Thickness}

My identification strategy exploits that mobility cost should only matter when workers are forced to switch occupations and mobility is necessary. To capture this source of variation empirically, I exploit that in a thick labor market it is more likely for a worker to find a vacancy that matches his skill endowment (see, e.g., Helsley and Strange (1990) and Section 4.2.1 of Moretti (2011) for a survey). Switching occupations is therefore less likely to be necessary.

I follow a popular approach in labor economics by assuming that local labor markets are well captured by

\footnotetext{
${ }^{4}$ See the data appendix A.2 for a detailed definition.
} 
the concept of Metropolitan Statistical Areas (MSA) as defined by the Office of Management and Budget (OMB) (e.g. Card, 2001; Mazzolari and Ragusa, 2011). ${ }^{5}$

I operationalize the concept of market thickness in two alternative ways. In both cases, the data comes from the Integrated Public Use Microdata Series (IPUMS-USA) 5\% sample of the U.S. Census for the years 1990 and 2000 (Ruggles et al., 2010). ${ }^{6}$

\subsubsection{Market Size}

The main measure of market thickness that I use in this paper is the size of an MSA's labor force, $S I Z E_{m}$. The motivation is that if workers and firms (vacancies) are heterogeneous in their skill endowments and requirements, an increase in trading partners increases the probability that a worker can find a vacancy that matches his skills. I refer the reader to the model in appendix A.1 for a more formal explanation of this mechanism.

\subsubsection{Industrial Diversity}

As an alternative measure, I use the (inverse) industry fractionalization of a local market $m$ that is equivalent to the Herfindahl concentration index. ${ }^{7}$ The measure is formally defined as

$$
1-\operatorname{DIVERSITY}_{m}=\sum_{k} \tau_{m k}^{2}
$$

where $\tau_{m k}$ is the employment share of industry $k$ in local labor market $m$. It captures the probability that two individuals who are randomly sampled from local labor market $m$ are employed in the same industry.

The motivation for using this measure is based on two observations. Firstly, as I report in detail in appendix A.3, most occupations can be found in many different industries. Secondly, as I document in Section 4, as long as workers stay in the same occupation, workers can switch industries without suffering a wage-loss. ${ }^{8}$ That is, SVP captures purely occupation-specific training that is transferable across industries.

\footnotetext{
${ }^{5}$ Competing concepts are to use U.S. states (Topel, 1986; Herz and van Rens, 2015), counties (Gould et al., 2002), or so-called commuting zones (Tolbert and Killian, 1987; Tolbert and Sizer, 1996; Autor et al., 2013). See the appendix A.2.1 of Dorn (2009) for a detailed discussion of local labor market concepts.

${ }^{6}$ There are some challenges to matching the CPS-DWS data to U.S. Census data. Between 1988 to 2012, the CPS-DWS uses three different MSA classifications. In 1988 and 1992 it uses the U.S. Office of Management and Budget (OMB) 84 definitions, from 1994 to 2004 the OMB 93 definitions, and from 2006 on the OMB 2003 definitions. Throughout this paper I use the OMB 2003 classification by using a "geographic relationship file" provided by the Census that can be found at https://www.census.gov/population/ metro/data/other.html.

${ }^{7}$ Measures of fractionalization have been widely used in economic research, in particular to analyze the impact of ethnic diversity on corruption, conflict, and various economic or political outcome variables (e.g., Mauro, 1995; Easterly and Levine, 1997; Alesina et al., 1999; Miguel and Gugerty, 2005).

${ }^{8}$ For example when an electrician is switches occupations and works as a waiter, he will lose his specific training. However, when a workers switches from being an electrician in the autmotive industry to the mining industry he does not lose his specific vocational preparation.
} 
In a market with high DIVERSITY ${ }_{m}$, employment - and therefore vacancies - is evenly spread across many industries. Assuming that industries' vacancy posting is subject to random fluctuations that are not perfectly correlated, this implies that the likelihood that at a given time there is no opening for a specific occupation in the local market is decreasing in DIVERSITY ${ }_{m} .{ }^{9}$ The probability that a worker can find a vacancy that matches his skills is therefore increasing in DIVERSITY ${ }_{m}$. I again refer the reader to appendix A.1 for a more formal explanation of the mechanism.

To facilitate the interpretation of the estimates, I transform both variables by generating empirical cumulative distribution functions. The new variables can then be interpreted as, firstly, the percentage of the total U.S. metropolitan labor force that resides in a MSA of equal or smaller size, and secondly, the percentage of the U.S. metropolitan workforce that lives in a MSA with equal or lower industrial diversity. For convenience, in the following I refer to both SIZE $_{m}$ and DIVERSITY ${ }_{m}$ as measures of labor market thickness.

\section{Basic Estimation Framework}

The relation between wait unemployment, mobility cost, and specific vocational preparation can be described by the following two regression equations. The first regression is estimated on the sub-sample of "switchers," that is, workers whose pre- and post-displacement occupation is not the same:

$$
M C_{i j t}=\alpha_{1}+\alpha_{2} S V P_{j}+\theta^{\prime} \mathbf{X}_{\mathbf{i}}+\epsilon_{i j t}
$$

The second regression is estimated on the sub-sample of "stayers," that is, workers whose pre- and postdisplacement occupation is the same:

$$
U N E M_{i j t}=\beta_{1}+\beta_{2} M C_{i j t}+\theta^{\prime} \mathbf{X}_{\mathbf{i}}+\eta_{i j t}
$$

$M C_{i j t}$ is the mobility cost of a displaced worker $i$ measured as the (expected) wage-loss (the log-earnings difference) he would suffer when leaving his pre-displacement occupation $j$.

The first regression captures the effect of specific human capital on mobility cost, visualized in Figure 1: conditional on switching to another occupation after displacement, there is a strong positive correlation between the extent of occupation-specific training a worker invested in and the wage-loss he experiences. This implies $\alpha_{2}>0$. As described in Section 2.2, I proxy the occupation-specific training by the length of the required specific training of the worker's last occupation, $S V P_{j}$.

\footnotetext{
${ }^{9}$ Note that this line of reasoning is related to the "risk diversficiation hypothesis" (e.g., Simon (1988) and Neumann and Topel (1991)).
} 
The second regression formalizes the idea of wait unemployment. The higher the (expected) mobility cost $M C_{i j t}$ a worker is facing, the longer the unemployment spell $U N E M_{i j t}$ he is willing to go through in order to evade switching occupations. UNEM $M_{i j t}$ is measured as the natural logarithm of 1 plus the weeks of unemployment: $\log \left(1+\right.$ weeks $\left._{i j t}\right) \cdot{ }^{10}$ If wait unemployment matters, it should hold $\beta_{2}>0$.

All regressions also include a vector of worker-specific demographic control variables $\mathbf{X}_{\mathbf{i}}$ to reconcile the model with the data and account for the fact that in reality workers differ among many more dimensions than the ones captured by the simple model. Regressions include year-of-displacement dummies, four education dummies (dropout, high-school, some college, college or more), a female dummy, a non-black dummy, and potential experience (quadratic). Importantly, all regressions also include the tenure on the pre-displacement job (cubic). The wage-loss captured by coefficient $\alpha_{2}$ in regression (2), for example, is therefore purely due to specific vocational training, not due to job tenure. As explained in the data appendix A.2, it is also important to take into account whether a worker was displaced due to plant closing. In order to capture this, all regressions include a plant closing dummy that is also interacted with worker-specific demographic variables.

I report estimates of equation (2) in the next section. I then turn to equation (3) in Section 5.

\section{Specific Human Capital and Mobility Cost}

Regression equation (2) relates to a big literature in labor economics that studies the specificity of human capital by analyzing earnings losses of displaced workers. Early papers in this literature try to shed light on the degree of firm-specificity of human capital (Abraham and Farber, 1987; Altonji and Shakotko, 1987; Kletzer, 1998; Topel, 1991) while Neal (1995) and Parent (2000) analyze the costs of switching industry. More recently, there is growing evidence that human capital is actually mostly occupation-specific (e.g., Kambourov and Manovskii, 2009).

Here I contribute to this literature by showing that the extent of human capital lost upon leaving an occupation also differs substantially across occupations. In particular, I show that the $S V P_{j}$ of an occupation is a good predictor of the extent of human capital lost upon switching. For example, a physician who underwent lengthy and highly specific occupational training will lose a substantial amount of human capital upon leaving his occupation. This is reflected in a high wage-loss. On the other hand, for workers in occupations that make use of mostly general skills (e.g., bartender, cashier) switching occupations entails only a limited loss of human capital resulting in only marginal wage-losses.

Column (1) of Table 2 reports estimates of equation (2). The coefficient on $S V P_{j}$ is positive and significant

\footnotetext{
${ }^{10}$ The results in this paper are robust to instead using $\log \left(w_{e e k s}{ }_{i j t}\right)$ and dropping observations with an "unemployment spell" of zero weeks. Additionally, I report Tobit estimates in Table 12 in the appendix.
} 
Table 2: Mobility Cost and SVP

\begin{tabular}{|c|c|c|c|c|c|c|c|}
\hline & (1) & (2) & (3) & (4) & (5) & (6) & (7) \\
\hline $\mathrm{SVP}_{j}$ & $\begin{array}{l}0.144^{* * *} \\
(0.0266)\end{array}$ & & & $\begin{array}{l}0.00613 \\
(0.0240)\end{array}$ & & & \\
\hline SWITCHER $_{i j t}$ & & $\begin{array}{c}0.0778^{* * *} \\
(0.0117)\end{array}$ & $\begin{array}{l}-0.0241 \\
(0.0263)\end{array}$ & $\begin{array}{l}0.00321 \\
(0.0231)\end{array}$ & $\begin{array}{l}-0.0478 \\
(0.0301)\end{array}$ & $\begin{array}{l}-0.0421 \\
(0.0272)\end{array}$ & \\
\hline $\mathrm{SVP}_{j} \times \mathrm{SWITCHER}_{i j t}$ & & & $\begin{array}{l}0.160^{* * *} \\
(0.0330)\end{array}$ & $\begin{array}{l}0.131^{* * *} \\
(0.0295)\end{array}$ & $\begin{array}{l}0.200^{* * *} \\
(0.0416)\end{array}$ & $\begin{array}{l}0.188^{* * *} \\
(0.0363)\end{array}$ & \\
\hline IND SWITCHER $_{i j t}$ & & & & & & & $\begin{array}{l}0.00900 \\
(0.0583)\end{array}$ \\
\hline $\mathrm{SVP}_{j} \times \mathrm{IND} \mathrm{SWITCHER}_{i j t}$ & & & & & & & $\begin{array}{c}0.0223 \\
(0.0731) \\
\end{array}$ \\
\hline Observations & 7,918 & 12,355 & 12,355 & 12,355 & 4,832 & 8,604 & 4,046 \\
\hline R-squared & 0.071 & 0.127 & 0.129 & 0.067 & 0.146 & 0.152 & 0.193 \\
\hline Occupation fixed effects & no & yes & yes & no & yes & yes & yes \\
\hline \multicolumn{8}{|l|}{ Sample } \\
\hline Occupation switchers only & yes & no & no & no & no & no & no \\
\hline Occupation stayers only & no & no & no & no & no & no & yes \\
\hline Plant closing only & no & no & no & no & yes & no & no \\
\hline No advance notice only & no & no & no & no & no & yes & no \\
\hline
\end{tabular}

Notes: Column (1) reports estimates of regression (2) whereas columns (2)-(7) report estimates of variations of regression equation (4). The method of estimation is least squares. The dependent variable is the wage-loss defined as the log-difference between deflated weekly earnings on the predisplacement jobs and the current job. All regressions include year-of-displacement dummies, four education dummies (dropout, high-school, some college, college or more), a female dummy, a non-black dummy, potential experience (quadratic), tenure on the pre-displacement job (cubic), and controls that capture whether displacement was due to plant closing. Only the sub-sample of displaced workers who report that the current job was the first job after displacement is used for estimation. As noted at the bottom of the table, the sample is further restricted in columns (1) and columns (5)-(7). Standard errors clustered at the occupation level are reported in parenthesis. ***,**, and * indicate significance at the $1 \%, 5 \%$, and $10 \%$ levels.

at the $1 \%$ level. As described in Section 2.2, $S V P_{j}$ is the share of the workforce that works in occupations requiring less or equal specific vocational preparation than occupation $j$. The estimates therefore imply that every 10 percentage point increase in the SVP distribution leads to a 1.4 percentage point increase in the expected wage-loss when switching occupations after displacement. This magnitude is economically important.

A problem with this simple specification is that I cannot for occupation fixed effects. It is therefore possible that the estimated positive coefficient on $S V P_{j}$ results from unobserved occupation characteristics that systematically vary with $S V P_{j}$. My baseline is therefore the modified regression

$$
M C_{i j t}=\alpha_{1} \text { SWITCHER }_{i j t}+\alpha_{2} \text { SWITCHER }_{i j t} \times S V P_{j}+\chi_{j}+\theta^{\prime} \mathbf{X}_{\mathbf{i}}+\epsilon_{i j t} .
$$

This regression includes occupation fixed effects $\chi_{j}$ and is estimated on the whole sample of displaced workers, including both occupation stayers and switchers. SWITCHER $i j t$ is a dummy variable that indicates whether individual $i$ with pre-displacement occupation $j$ found a job in the same occupation.

The estimation follows a difference-in-differences approach. I compare the wage-loss of occupation switchers 
relative to stayers across occupations characterised by low and high specific vocational preparation. The estimate of interest is therefore the coefficient on the interaction $S W I T C H E R_{i j t} \times S V P_{j}$. Note that the mean effect of $S V P_{j}$ is captured by the occupation fixed effects $\chi_{j}$.

Regression estimates are shown in columns (2) to (7) of Table 2. In column (2) I report estimates from a simplified model that does not include $S W I T C H E R_{i j t} \times S V P_{j}$ as a regressor. Switching occupations goes along with a wage-loss as the coefficient on SWITCHER $R_{i j t}$ is highly significant. This finding is not new (Kambourov and Manovskii, 2009, e.g.).

I contribute to this literature by showing that this simple model masks substantial heterogeneities. In the full model in column (3) the coefficient on the interaction $S W I T C H E R_{i j t} \times S V P_{j}$ is estimated to be positive and highly significant while the coefficient on the main effect $S W I T C H E R_{i j t}$ is not significantly different from zero anymore. This implies that switching occupations per se does not lead to a wage-loss. However, switching is costly for workers who made substantial investments in specific vocational preparation. The magnitude is economically important: the expected differential wage-loss is increasing by about 1.6 percentage points for a 10 percentage points increase of $S V P_{j}$. This implies, for example, that the differential expected wage-loss upon leaving an occupation is about 10 percentage points higher for an electrician (83\% percentile) compared to a waiter ( $22 \%$ percentile).

Column (4) reports estimates when occupation fixed effects are not included and the mean effect of $S V P_{j}$ is therefore identified. Interestingly, the estimated coefficient on $S V P_{j}$ is not significantly different from zero, meaning that conditional on staying in the same occupation, the wage-loss workers suffer does not differ by the required specific vocational preparation of an occupation. This is reassuring evidence that $S V P_{j}$ is indeed mostly capturing occupation-specific training and not firm- or match-specific human capital.

Columns (5) and (6) show results when the sample is restricted further. Column (5) reports estimates when only workers who report having been displaced due to plant closing are included. As discussed in the data appendix A.2, this sample is arguably preferable to my overall sample because in this case weak performance on the job cannot have been the reason for displacement and therefore estimates will be less subject to criticism regarding selection bias. The coefficient on the interaction gets larger, implying that estimates based on my baseline sample might be subject to some selection effects.

In column (6) the sample is restricted to workers who did not receive an advance notice of displacement, see appendix A.2. Again, results are larger than in the baseline. This suggests that the benefits of on-the-job-search are the higher the more specific a worker's training is. In order to account for this effect, I will use the sub-sample of workers who were not noticed in advance of their displacement as my baseline sample when estimating regression (3) in Section 5.1. 
In column (7) I restrict the sample to workers who did not switch occupations. At the same time I add a dummy that captures whether a worker stayed in the same industry after displacement or not. The coefficient on the interaction and the mean effect are both not significantly different from zero. This corroborates evidence from column (4): $S V P_{j}$ indeed captures human capital that is occupation- but not industry-specific.

\section{Estimates of Wait Unemployment}

\subsection{Reduced Form Estimates}

Equation (3) captures the concept of wait unemployment: there is a trade-off between unemployment duration and mobility cost. Switching occupations and leaving behind occupation-specific human capital can entail high wage-losses. Facing such mobility costs workers might be willing to accept long unemployment spells in order to evade switching and secure reemployment in their old occupation instead. My objective is to empirically quantify this trade-off.

A problem hindering estimation is that the (expected) wage-loss a worker faces upon leaving his predisplacement occupation $M C_{i j t}$ is by definition not observed for the sub-sample of occupation stayers equation (3) is estimated on. Furthermore, any reasonable measure of mobility $\operatorname{cost} M C_{i j t}$ and the worker's unemployment duration $U N E M_{i j t}$ are likely to be simultaneously determined. That is, not only might mobility cost incentivize workers to sit through long spells of wait unemployment, but long unemployment spells might also weaken the bargaining position of workers and therefore lead to lower wages and lower mobility cost. This would lead to a downward bias in the estimation results. I therefore combine equations (2) and (3) into the following reduced form equation:

$$
U N E M_{i j t}=\gamma_{1}+\gamma_{2} S V P_{j}+\theta^{\prime} \mathbf{X}_{\mathbf{i}}+v_{i j t}
$$

Unlike the mobility $\operatorname{cost} M C_{i j t}, S V P_{j}$ is directly observable from the Dictionary of Occupational Titles as explained in detail in Section 2. Moreover, $S V P_{j}$ is arguably a pre-determined variable and endogeneity should therefore be much less of a problem.

However, a second challenge for estimation remains. As before the (likely) presence of occupation fixed effects might result in biased estimates. Occupations associated with high mobility cost might differ in other - potentially unobserved - characteristics from occupations subject to low mobility cost. For example, service occupations might require only few specific vocational preparation and workers therefore are likely to face small mobility cost upon switching occupations. Nevertheless, these workers might have above-average unemployment spells, for example, because of permanent low demand for their skills. When using cross- 
occupation variation for identification it is difficult to distinguish the effect of variation in mobility cost (I am interested in) from variation in other unobserved occupation characteristics that systematically vary with mobility cost.

To avoid potential omitted variable bias I therefore rely on within-occupation differences for identification. To do so I exploit geographic variation: as formalized in the appendix, the higher the thickness a local labor market, the less likely is it that displaced workers need to switch occupations; potential mobility cost are less likely to be binding. I estimate the following regression equation on the sub-sample of occupation stayers:

$$
\text { UNEM }_{i j m t}=\gamma_{1} \text { THIN_MARKET } m+\gamma_{2} \text { THIN_MARKET } m \text { } \times S V P_{j}+\chi_{j}+\theta^{\prime} \mathbf{X}_{\mathbf{i}}+v_{i j m t}
$$

The mean effect of $S V P_{j}$ is captured by the occupation fixed effects $\chi_{j}$. The estimation strategy follows the same logic as a standard difference-in-differences approach. However, note that both THIN $M A R K E T_{m}$ and $S V P_{j}$ are continuous measures. The hypothesis is that highly specialized workers sit through long unemployment spells in order to evade switching occupations. Since in a thin market $m$ it is less likely to be able to find a job in the same occupation, this effect should be increasing in THIN MARKET ${ }_{m}$. The estimate of interest is therefore the coefficient on the interaction THIN $M A R K E T_{m} \times S V P_{j}$. Under the hypothesis that wait unemployment is an important driving force of unemployment it should hold $\gamma_{2}>0$.

\subsubsection{Main Results}

Table 3 shows results when market thickness is operationalized as the size of the local labor force. Again, all specifications contain typical demographic controls and tenure on the previous job. Furthermore, occupation fixed effects, year-of-displacement fixed effects, state fixed effects, and controls capturing whether displacement was due to plant closing are part of all specifications. Mean effects and the constant are estimated but not shown. Results in column (1) indicate a coefficient estimate for the interaction term that is positive and statistically significant at the 1-percent level. Adding a linear state time trend in column (2) does not change the results. Adding MSA fixed effects in (3) slightly decreases the size of the coefficient. ${ }^{11}$ The estimates imply that there is a significant differential effect of the required specific vocational preparation of an occupation on unemployment duration. The thinner a local market is, the stronger is the effect of $S V P_{j}$ on the length of the unemployment spell.

The difference-in-differences setting makes it difficult to interpret the magnitude of the estimated effect. I therefore follow Rajan and Zingales (1998) and report a differential unemployment spell for each specification in

\footnotetext{
${ }^{11}$ State fixed effects do not completely drop out in this specification because some metropolitan areas span more than one state. Results are not affected when a state time trend is included.
} 
Table 3: Reduced Form Estimates: Market Size

\begin{tabular}{|c|c|c|c|c|c|c|}
\hline & (1) & (2) & (3) & (4) & (5) & (6) \\
\hline$\left(1-\mathrm{SIZE}_{m}\right) \times \mathrm{SVP}_{j}$ & $\begin{array}{l}0.991^{* * *} \\
(0.381)\end{array}$ & $\begin{array}{l}1.134^{* * *} \\
(0.405)\end{array}$ & $\begin{array}{l}0.880^{*} \\
(0.507)\end{array}$ & $\begin{array}{l}1.506^{* * *} \\
(0.541)\end{array}$ & $\begin{array}{l}1.555^{* *} \\
(0.654)\end{array}$ & $\begin{array}{l}1.953^{* *} \\
(0.838)\end{array}$ \\
\hline $\begin{array}{l}\text { Observations } \\
\text { R-squared }\end{array}$ & $\begin{array}{l}1,604 \\
0.369\end{array}$ & $\begin{array}{l}1,604 \\
0.388\end{array}$ & $\begin{array}{l}1,604 \\
0.485\end{array}$ & $\begin{array}{c}533 \\
0.451\end{array}$ & $\begin{array}{c}533 \\
0.519\end{array}$ & $\begin{array}{c}533 \\
0.692\end{array}$ \\
\hline $\begin{array}{l}\text { Diff unem spell } \\
\text { Diff unem spell (weeks) }\end{array}$ & $\begin{array}{l}0.281 \\
1.810\end{array}$ & $\begin{array}{l}0.328 \\
2.027\end{array}$ & $\begin{array}{l}0.246 \\
2.112\end{array}$ & $\begin{array}{l}0.457 \\
2.304\end{array}$ & $\begin{array}{l}0.475 \\
1.864\end{array}$ & $\begin{array}{l}0.630 \\
4.091\end{array}$ \\
\hline $\begin{array}{l}\text { Occupation fixed effect } \\
\text { State fixed effect } \\
\text { State time trend } \\
\text { MSA fixed effect }\end{array}$ & $\begin{array}{l}\text { yes } \\
\text { yes } \\
\text { no } \\
\text { no }\end{array}$ & $\begin{array}{l}\text { yes } \\
\text { yes } \\
\text { yes } \\
\text { no }\end{array}$ & $\begin{array}{l}\text { yes } \\
\text { yes } \\
\text { yes } \\
\text { yes }\end{array}$ & $\begin{array}{l}\text { yes } \\
\text { yes } \\
\text { no } \\
\text { no }\end{array}$ & $\begin{array}{l}\text { yes } \\
\text { yes } \\
\text { yes } \\
\text { no }\end{array}$ & $\begin{array}{l}\text { yes } \\
\text { yes } \\
\text { yes } \\
\text { yes }\end{array}$ \\
\hline $\begin{array}{l}\text { Sample } \\
\text { Plant closing only }\end{array}$ & no & no & no & yes & yes & yes \\
\hline
\end{tabular}

Notes: The regressions are least squares estimates of equation (6). The dependent variable is the length of the unemployment spell $U N E M_{i j m t}$, measured as the natural logarithm of 1 plus the weeks of unemployment: $\log \left(1+w e e k s_{i j t}\right)$. I operationalize market thickness using the size of the local labor force. The differential unemployment spell reports the relative increase in the unemployment duration of a displaced worker with high SVP relative to a worker with low SVP (75th vs. 25th percentile) when located in a thick vs. thin local labor market (75th vs. 25th percentile). All regressions include year-ofdisplacement dummies, four education dummies (dropout, high-school, some college, college or more), a female dummy, a non-black dummy, potential experience (quadratic), tenure on the pre-displacement job (cubic), and controls that capture whether displacement was due to plant closing. Only the sub-sample of displaced workers who report not to have changed occupations after displacement, whose current job was the first job after displacement, who were not noticed in advance of their displacement, and who did not move after displacement is used for estimation. In columns (4) to (6) the sample is further restricted to workers who report to have been displaced due to plant closing. Standard errors clustered at the occupation level are reported in parenthesis. ${ }^{* *}, * *$, and $*$ indicate significance at the $1 \%, 5 \%$, and $10 \%$ levels.

Table 3. Consider two unemployed workers who have been displaced from occupations at the 25th and 75th SVP percentile, respectively. Think of the first as a waiter and of the latter as an electrician. According to the U.S. Census, only $25 \%$ of the labor force reside in metropolitan areas bigger than the Washington metropolitan area, the 6th biggest MSA in the United States. On the other hand, 75\% reside in MSAs bigger than Bakersfield, $C A$. For example, the estimates reported in columns (1) of Table 4 imply that the unemployment spell of the electrician would increase by 28.1 percentage points more than that of the waiter if both were re-located from the thick labor market in the Washington metropolitan area to Bakersfield, $C A .{ }^{12}$ In levels, this corresponds to about two weeks. ${ }^{13}$

In columns (4) to (6) I restrict the sample to workers who report having been displaced due to plant closing only. As discussed in the data appendix A.2, this sample is arguably preferable to my baseline sample that also includes workers who lost their job due an abolished shift and "insufficient work." If displaced workers have systematically lower ability and workers with lower ability in turn have lower specific vocational training,

\footnotetext{
${ }^{12}$ This number can be calculated from the estimated coefficients given in column (1) of Table 3 as $\exp \left((0.75-0.25)^{2} \times 0.991\right)-1 \approx 28.1 \%$.

${ }^{13}$ I follow Duan (1983) to retransform the dependent variable in logs back to levels. See also Section 3.6.3 in Cameron and Trivedi (2010).
} 
Table 4: Reduced Form Estimates: Industrial Diversity

\begin{tabular}{|c|c|c|c|c|c|c|}
\hline & (1) & (2) & (3) & (4) & (5) & (6) \\
\hline$\left(1-\operatorname{DIVERSITY}_{m}\right) \times \operatorname{SVP}_{j}$ & $\begin{array}{l}1.051^{* * *} \\
(0.385)\end{array}$ & $\begin{array}{l}1.210^{* * *} \\
(0.432)\end{array}$ & $\begin{array}{l}1.155^{* *} \\
(0.519)\end{array}$ & $\begin{array}{l}1.584^{* * *} \\
(0.467)\end{array}$ & $\begin{array}{l}1.811^{* * *} \\
(0.536)\end{array}$ & $\begin{array}{l}1.475^{* *} \\
(0.685)\end{array}$ \\
\hline $\begin{array}{l}\text { Observations } \\
\text { R-squared }\end{array}$ & $\begin{array}{l}1,604 \\
0.369\end{array}$ & $\begin{array}{l}1,604 \\
0.388\end{array}$ & $\begin{array}{l}1,604 \\
0.487\end{array}$ & $\begin{array}{l}1,024 \\
0.356\end{array}$ & $\begin{array}{l}1,024 \\
0.392\end{array}$ & $\begin{array}{l}1,024 \\
0.508\end{array}$ \\
\hline $\begin{array}{l}\text { Diff unem spell } \\
\text { Diff unem spell (weeks) }\end{array}$ & $\begin{array}{l}0.301 \\
2.077\end{array}$ & $\begin{array}{l}0.353 \\
2.301\end{array}$ & $\begin{array}{l}0.335 \\
2.879\end{array}$ & $\begin{array}{l}0.486 \\
3.202\end{array}$ & $\begin{array}{l}0.572 \\
3.346\end{array}$ & $\begin{array}{l}0.446 \\
4.354\end{array}$ \\
\hline $\begin{array}{l}\text { Occupation fixed effect } \\
\text { State fixed effect } \\
\text { State time trend } \\
\text { MSA fixed effect }\end{array}$ & $\begin{array}{l}\text { yes } \\
\text { yes } \\
\text { no } \\
\text { no }\end{array}$ & $\begin{array}{l}\text { yes } \\
\text { yes } \\
\text { yes } \\
\text { no }\end{array}$ & $\begin{array}{l}\text { yes } \\
\text { yes } \\
\text { yes } \\
\text { yes }\end{array}$ & $\begin{array}{l}\text { yes } \\
\text { yes } \\
\text { no } \\
\text { no }\end{array}$ & $\begin{array}{l}\text { yes } \\
\text { yes } \\
\text { yes } \\
\text { no }\end{array}$ & $\begin{array}{l}\text { yes } \\
\text { yes } \\
\text { yes } \\
\text { yes }\end{array}$ \\
\hline $\begin{array}{l}\text { Sample } \\
\text { Occs. in many inds. only }\end{array}$ & no & no & no & yes & yes & yes \\
\hline
\end{tabular}

Notes: The regressions are least squares estimates of equation (6). The dependent variable is the length of the unemployment spell $U N E M_{i j m t}$, measured as the natural logarithm of 1 plus the weeks of unemployment: $\log \left(1+w e e k s_{i j t}\right)$. I operationalize market thickness using the my measure of industrial diversity. In columns (6) to (10), I exclude occupations that are concentrated in few industries. The differential unemployment spell reports the relative increase in the unemployment duration of a displaced worker with high SVP relative to a worker with low SVP (75th vs. 25th percentile) when located in thick vs. thin local labor market (75th vs. 25th percentile). All regressions include year-of-displacement dummies, four education dummies (dropout, high-school, some college, college or more), a female dummy, a non-black dummy, potential experience (quadratic), tenure on the pre-displacement job (cubic), and controls that capture whether displacement was due to plant closing. Only the sub-sample of displaced workers who report not to have changed occupations after displacement, whose current job was the first job after displacement, who were not noticed in advance of their displacement, and who did not move after displacement is used for estimation. In columns (4) to (6) occupations present in only few industries are excluded. Standard errors clustered at the occupation level are reported in parenthesis. ${ }^{* * *}, * *$, and $*$ indicate significance at the $1 \%, 5 \%$, and $10 \%$ levels.

then this might result in an underestimation of the effect of $S V P_{j}$ on wait unemployment. Moreover, using this sample I can exclude that estimates are biased because workers expect to be recalled to their old job. Indeed, the estimated coefficients are larger than in the baseline sample and, in spite of the smaller sample, remain significantly different from zero. This suggests that estimates using the baseline sample represent a lower bound on wait unemployment.

\section{Industrial Diversity}

Table 4 reports results when market thickness is operationalized as the industrial diversity of the local labor market instead of the size of its labor force, see Section 2.3. Columns (1) to (3) document that the coefficient of interest remains significantly different from zero and of similar size to the estimates reported in Table 3.

A potential concern regarding the use of the industrial diversity measure is that the employment of some occupations is heavily concentrated in only few industries. For example, according to the 1990 U.S. Census, $83 \%$ of bakers are employed in the three industries Grocery stores, Bakery products, and Retail bakeries. For some occupations, the heavy concentration in one industry is almost by definition: for example, Hotel clerks are 
Table 5: Reduced Form Estimates: Occupation Switching

\begin{tabular}{lccccccccccc}
\hline \hline & $(1)$ & $(2)$ & $(3)$ & $(4)$ & $(5)$ & $(6)$ & $(7)$ & $(8)$ & $(9)$ & $(10)$ \\
\hline $\mathrm{SVP}_{j}$ & $-0.125^{*}$ & $-0.127^{*}$ & -0.0176 & -0.0209 & & & 0.0980 & 0.100 & \\
& $(0.0700)$ & $(0.0699)$ & $(0.0826)$ & $(0.0835)$ & & & $(0.0684)$ & $(0.0678)$ & \\
$\left(1-\mathrm{SIZE}_{m}\right) \times \mathrm{SVP}_{j}$ & & & $-0.203^{* *}$ & $-0.199^{* *}$ & $-0.195^{* *}$ & $-0.159^{*}$ & & & & \\
& & & $(0.0904)$ & $(0.0880)$ & $(0.0794)$ & $(0.0889)$ & & & \\
$\left(1-D I V E R S I T Y_{m}\right) \times \mathrm{SVP}_{j}$ & & & & & & & $-0.442^{* * *}$ & $-0.450^{* * *}$ & $-0.447^{* * *}$ & $-0.412^{* * *}$ \\
& & & & & & & $(0.104)$ & $(0.104)$ & $(0.105)$ & $(0.105)$ \\
\hline Observations & 4,372 & 4,372 & 4,372 & 4,372 & 4,372 & 4,372 & 4,372 & 4,372 & 4,372 & 4,372 \\
R-squared & 0.060 & 0.069 & 0.062 & 0.071 & 0.267 & 0.319 & 0.066 & 0.075 & 0.271 & 0.322 \\
Occupation fixed effect & no & no & no & no & yes & yes & no & no & yes & yes \\
State fixed effect & yes & yes & yes & yes & yes & yes & yes & yes & yes & yes \\
State time trend & no & yes & no & yes & yes & yes & no & yes & yes & yes \\
MSA fixed effect & no & no & no & no & no & yes & no & no & no & yes \\
\hline \hline
\end{tabular}

Notes: The regressions are least squares estimates of equation (7). The dependent variable is 0 if the pre- and post-displacement occupation of a displaced worker is the same and 1 if it is different. I operationalize market thickness using the size of the local labor force in columns (3) to (6) and as industrial diversity in columns (7) to (10). All regressions include year-of-displacement dummies, four education dummies (dropout, high-school, some college, college or more), a female dummy, a non-black dummy, potential experience (quadratic), tenure on the pre-displacement job (cubic), and controls that capture whether displacement was due to plant closing. The regression also controls for the length of the completed unemployment spell. The sample contains both workers who have and who have not changed occupations after displacement. The sample is restricted to workers whose current job was the first job after displacement, who were not noticed in advance of their displacement, and who did not move after displacement. Standard errors clustered at the occupation level are reported in parenthesis. ${ }^{* * *}, * *$, and ${ }^{*}$ indicate significance at the $1 \%, 5 \%$, and $10 \%$ levels.

employed in Hotels and motels and school teachers work in Elementary and secondary schools. Occupations like these should therefore not benefit from industrially diverse local labor markets.

To address this issue, I firstly document in appendix A.3 that such occupations are an exception and that employment in most occupations indeed spans many industries: the median worker is employed in an occupation that can be found in 48 different industries. Secondly, the fact that occupations differ in the degree to which they span different industries allows me to test an additional hypothesis: industrial diversity of a local labor market should be especially important for occupations that span a higher number of industries and should therefore have a relatively stronger effect on wait unemployment.

I explore this in columns (4)-(6) of Table 4 by excluding occupations that can be found in less than 24 different industries (that is, I exclude occupations ranked within the lower two quintiles according to their industry-span). In line with the hypothesis, the coefficient of interest increases substantially in size.

\subsubsection{Occupation Switching}

My interpretation of the results reported in Tables 3 and 4 is that workers endowed with specific human capital face high mobility costs when switching occupations and are therefore willing to go through long unemployment spells in order to find a job in the same occupation. If this is true, we would expect workers with low SVP to be more likely to switch occupations, especially when located in thin labor markets where it 
difficult to find a job in the same occupation. I estimate the following regression equation:

$$
\text { SWITCHER }_{i j m t}=\delta_{1} S V P_{j}+\delta_{2} \text { THIN_MARKET } m+\delta_{3} \text { THIN_MARKET } m \text { } \times S V P_{j}+\theta^{\prime} \mathbf{X}_{\mathbf{i}}+\omega_{i j m t}
$$

(Pre-displacement) occupation fixed effects, year-of-displacement fixed effects, state fixed effects, and controls capturing whether displacement was due to plant closing are part of all specifications. Columns (1) and (2) of Table 5 report estimates of a simplified model that assumes $\delta_{2}=0$ and $\delta_{3}=0$. I find that workers endowed with more specific human capital are indeed more likey to stay in their pre-displacement occupation. In columns (3) and (4) I show results of the full model that allows the effect of SVP to differ depending on the thickness of the local labor market. The estimates are consistent with wait unemployment. SVP does not have an effect on switching behavior in very thick labor markets $\left(\left(1-S I Z E_{m}\right)=0\right)$ since being able to stay in the same occupation is less difficult. The thinner the market, however, the more likely are workers with non-specific human capital to switch. The effects are quantitatively important. To use the example from above, estimates in column (3) imply that in the thick Washington metropolian area market a worker at the 25 percentile of SVP (a waiter) is $3.4 \%$ percentage points more likely to switch than one at the 75 percentile (an electrician). In the relatively thin Bakersfield, CA market, however, this differene increases to 8.5 percentage points. ${ }^{14}$

In column (5) I include occupation fixed effects and $S V P_{j}$ is therefore no longer identified. The coefficient on THIN_MARKET $T_{m} \times S V P_{j}$ remains almost unchanged and only becomes slightly smaller when MSA fixed effects are added in column (6). The results become quantitatively stronger when the industrial diversity measure is used in columns (7) to (10).

\subsubsection{Triple Differences}

One might argue that the estimates reported in Section 5.1.1 are compatible with other mechanisms than wait unemployment. The interaction THIN MARKET $T_{m} \times S V P_{j}$ might be just a proxy for another, unobserved channel. In particular, workers with highly specific training might benefit disproportionally from thick labor markets due to reasons not related to wait unemployment.

Here I therefore use the sample of both occupation stayers and switchers to construct another test. Wait unemployment means that displaced workers sit through long unemployment spells in order to stay in the occupation they have been trained for. If the long unemployment spells I observe in the data are indeed due to wait unemployment, I should therefore observe these long spells only for occupation stayers, but not for switchers. In this section I show that this is indeed the case with my data.

I estimate a difference-in-difference-in-differences regression on the sample including both occupation stayers

$\overline{{ }^{14} \text { These figures can be calculated as }-0.0176 \times(-0.5)+0.25} \times(-0.5) \times(-0.203)=.034$ and $-0.0176 \times(-0.5)+0.75 \times(-0.5) \times(-0.203)=.085$. 
Table 6: Reduced Form Estimates: Triple Differences

\begin{tabular}{|c|c|c|c|c|c|c|c|c|c|c|}
\hline & (1) & (2) & (3) & (4) & (5) & (6) & (7) & (8) & (9) & (10) \\
\hline$\left(1-\mathrm{SIZE}_{m}\right) \times \mathrm{SVP}_{j}$ & $\begin{array}{l}0.737^{* *} \\
(0.356)\end{array}$ & $\begin{array}{l}0.750^{* *} \\
(0.356)\end{array}$ & $\begin{array}{c}0.540 \\
(0.357)\end{array}$ & $\begin{array}{l}1.336^{* *} \\
(0.528)\end{array}$ & $\begin{array}{l}1.424^{* * *} \\
(0.546)\end{array}$ & & & & & \\
\hline SWITCHER $_{i j m t} \times\left(1-\mathrm{SIZE}_{m}\right) \times \mathrm{SVP}_{j}$ & $\begin{array}{l}-0.333 \\
(0.556)\end{array}$ & $\begin{array}{l}-0.408 \\
(0.551)\end{array}$ & $\begin{array}{r}-0.0922 \\
(0.497)\end{array}$ & $\begin{array}{l}-1.285 \\
(1.006)\end{array}$ & $\begin{array}{l}-1.115 \\
(0.909)\end{array}$ & & & & & \\
\hline$\left(1-\right.$ DIVERSITY $\left._{m}\right) \times \mathrm{SVP}_{j}$ & & & & & & $\begin{array}{l}0.716^{*} \\
(0.365)\end{array}$ & $\begin{array}{l}0.759^{* *} \\
(0.375)\end{array}$ & $\begin{array}{c}0.636 \\
(0.386)\end{array}$ & $\begin{array}{l}1.294^{* * *} \\
(0.442)\end{array}$ & $\begin{array}{c}1.163^{* * *} \\
(0.445)\end{array}$ \\
\hline SWITCHER $_{i j m t} \times\left(1-\right.$ DIVERSITY $\left._{m}\right) \times \operatorname{SVP}_{j}$ & & & & & & $\begin{array}{l}-0.982^{* *} \\
(0.487)\end{array}$ & $\begin{array}{l}-1.051^{* *} \\
(0.507) \\
\end{array}$ & $\begin{array}{l}-0.939^{*} \\
(0.517)\end{array}$ & $\begin{array}{c}-1.609^{* *} \\
(0.619)\end{array}$ & $\begin{array}{c}-1.634^{* * *} \\
(0.560)\end{array}$ \\
\hline Observations & 4,372 & 4,372 & 4,372 & 1,365 & 1,365 & 4,372 & 4,372 & 4,372 & 3,048 & 3,048 \\
\hline R-squared & 0.229 & 0.242 & 0.289 & 0.345 & 0.449 & 0.229 & 0.242 & 0.289 & 0.228 & 0.291 \\
\hline Total effect switchers & 0.403 & 0.342 & 0.448 & 0.0509 & 0.309 & -0.266 & -0.292 & -0.303 & -0.315 & -0.470 \\
\hline P-value & 0.200 & 0.273 & 0.138 & 0.944 & 0.646 & 0.334 & 0.307 & 0.309 & 0.360 & 0.130 \\
\hline Occupation fixed effect & yes & yes & yes & yes & yes & yes & yes & yes & yes & yes \\
\hline State fixed effect & yes & yes & yes & yes & yes & yes & yes & yes & yes & yes \\
\hline State time trend & no & yes & yes & yes & yes & no & yes & yes & yes & yes \\
\hline MSA fixed effect & no & no & yes & no & yes & no & no & yes & no & yes \\
\hline \multicolumn{11}{|l|}{ Sample } \\
\hline Plant closing only & no & no & no & yes & yes & no & no & no & no & no \\
\hline Occs. in many inds. only & no & no & no & no & no & no & no & no & yes & yes \\
\hline
\end{tabular}

Notes: The regressions are least squares estimates of equation (8). The dependent variable is the length of the unemployment spell $U N E M_{i j m t}$, measured as the natural logarithm of 1 plus the weeks of unemployment: $\log \left(1+\right.$ weeks $\left.s_{i j t}\right)$. I operationalize market thickness using the size of the local labor force in columns $(1)$ to (5) and industrial diversity in columns (6) to (10). The row labeled "total interaction switchers" shows the sum of coefficients THIN_MARKET $m \times$ SVP $_{j}$ and $S W I T C H E R_{i j m t} \times$ THIN_MARKET $m$. $\times S V P_{j}$. All regressions include year-of-displacement dummies, four education dummies (dropout, high-school, some college, college or more), a female dummy, a non-black dummy, potential experience (quadratic), tenure on the pre-displacement job (cubic), and controls that capture whether displacement was due to plant closing. The sample contains both workers who have and who have not changed occupations after displacement. The sample is restricted to workers whose current job was the first job after displacement, who were not noticed in advance of their displacement, and who did not move after displacement. In columns (4) and (5) the sample is further restricted to workers who report to have been displaced due to plant closing. In columns (9) and (10) occupations present in only few industries are excluded. Standard errors clustered at the occupation level are reported in parenthesis. $* * * * *$, and * indicate significance at the $1 \%, 5 \%$, and $10 \%$ levels.

and switchers by adding a third interaction to regression (6):

$$
\begin{aligned}
\text { UNEM }_{i j m t} & =\gamma_{1} \text { SWITCHER }_{i j m t}+\gamma_{2} \text { THIN MARKET } \\
& \times S V P_{j}+\gamma_{3} \text { THIN_MARKET }_{m} \times \text { SWITCHER }_{i j m t} \\
& +\gamma_{4} \text { SWITCHER }_{i j m t} \times S V P_{j}+\gamma_{5} \text { THIN_MARKET } \\
m & \times S V P_{j} \times \text { SWITCHER }_{i j m t}+\chi_{j}+\theta^{\prime} \mathbf{X}_{\mathbf{i}}+v_{i j m t}
\end{aligned}
$$

SWITCHER $R_{i j m t}$ is a dummy variable that indicates whether individual $i$ with pre-displacement occupation $j$ found a job in the same occupation. The coefficient on the interaction THIN $M A R K E T_{m} \times S V P_{j}$ captures the effect of mobility cost on unemployment duration whereas the coefficient on THIN $M A R K E T_{m} \times S V P_{j} \times S W I T C H E R_{i j m t}$ is the differential effect on workers who report to have switched occupations.

Columns (1) to (5) of Table 6 report results when market thickness is operationalized as the size of the local labor force. The coefficients for occupation stayers are slightly smaller in magnitude than in the baseline in Table 3. As before, the results become stronger once the sample is restricted to workers who report having been displaced due to plant closing only in columns (4) and (5). Importantly, the effect for switchers is never significantly different from zero, see the row labeled "total effect switchers" in the table. ${ }^{15}$ As reported in

\footnotetext{
${ }^{15}$ Note that occupation switchers are most likely also somewhat affected by wait unemployment. Workers might first try to find work
} 
columns (6) to (10) of Table 6, the results also hold when market thickness is operationalized as industrial diversity. As before, the results become stronger when occupations concentrated in few industries are excluded from the sample in columns (9) and (10).

\subsubsection{Geographic Mobility}

Another potential concern is geographic mobility. Some workers might manage to stay in the same occupation without going through a spell of wait unemployment by moving to another labor market. In Table 10 in the appendix I report estimates of the regression equation

$$
\text { SWITCHER }_{i j m t}=\delta_{1} \operatorname{MOVED}_{i j m t}+\delta_{2} \operatorname{MOVED}_{i j m t} \times S V P_{j}+\chi_{j}+\theta^{\prime} \mathbf{X}_{\mathbf{i}}+\omega_{i j m t} .
$$

MOVED $D_{i j m t}$ equals 1 if a displaced worker reports to have moved cities after displacement and 0 otherwise. I find that displaced workers who report to have moved cities are indeed more likely to stay in their predisplacement occupation, especially when endowed with high SVP. Geographic mobility reduces the number of unemployed in slack local labor markets and therefore leads to a reduction of wait unemployment for the remaining workers. Since, as explained in the data appendix, the estimates presented above are based on the sample of displaced workers who report not to have moved cities after displacement they implicitly take the effect of geographic mobility into account. ${ }^{16}$

\subsection{Instrumental Variable Estimates}

In the last section I showed evidence that workers endowed with more specific training are willing to go through disproportionately long spell of unemployment in order to evade switching occupations. I now push the analysis further and directly estimate the effect of mobility cost on wait unemployment captured by equation (3). In order to do so, I make the additional identifying assumption that $S V P_{j}$ affects unemployment duration only through the mobility cost a worker is facing. I can then estimate equation (3) by using $S V P_{j}$ as an instrument for the mobility cost $M C_{i j t} .{ }^{17}$ To control for occupation fixed effects, I use the same difference-in-differences

in their original occupation and only after learning that few vacancies are around decide to switch. One can also interpret this as a measurement problem. In the data workers only report in what occupation they eventually found a job and how many weeks it took them to find this job. It is not clear how the time spend searching was distributed among finding a job in their pre-displacement occupation vs. finding a job in another occupation.

${ }^{16}$ As suggested by an anonymous referee, there are some other tests one might construct in order to further explore whether observed geographic mobility is in line with wait unemployment. For example, one would expect a higher probability of moving cities for high SVP workers displaced in thin labor markets. Unfortunately, the CPS Displaced Workers Supplement only contains the worker's MSA of residence at the time of the interview, not at the time of displacement. The local labor market where a worker was displaced can therefore not be inferred for workers who report to have moved after displacement.

${ }^{17}$ Note that $S V P$ only needs to be $a$ source of exogenous variation in mobility costs. It does not need to be the only source or even the main source of exogenous variation. 
approach as in regression (6). Based on equation (3), the second-stage can then be written as

$$
U N E M_{i j m t}=\beta_{1} \text { THIN_MARKET } T_{m}+\beta_{2} \text { THIN_MARKET } T_{m} \times M C_{i j m t}+\chi_{j}+\theta^{\prime} \mathbf{X}_{\mathbf{i}}+\eta_{i j m t} .
$$

A challenge to use two-stage least squares in my setting is that mobility cost $M C_{i j m t}$ are only observed for the sample of occupation switchers while the dependent variable in equation (10) is the unemployment duration of stayers. That is, the endogenous regressor and the dependent variable are not part of the same sub-sample.

As first shown in an influential article by Angrist and Krueger (1992), under certain conditions estimation is still feasible by using the two-sample two-stage least squares (TS2SLS) procedure. ${ }^{18}$ The principal idea of TS2SLS is that the first- and second-stage can be estimated on two separate samples as long as all control variables and the instrument are present in both samples, and - as it is the case here - both samples have been drawn from the same population. Since the distribution of observable characteristics might vary between the samples of switchers and stayers, it is important to note that this is implicitly corrected for by the TS2SLS estimator and estimates remain consistent (see footnote 1 in Inoue and Solon (2010)).

The estimate of interest in regression (10) is the coefficient on the interaction THIN $M A R K E T_{m} \times M C_{i j m t}$ where the mobility cost $M C_{i j m t}$ is likely to be endogenous. I therefore use THIN $M A R K E T_{m} \times S V P_{j}$ as an instrument for this interaction. ${ }^{19}$ The first-stage regression on the sample of switchers is then given by

$$
\text { THIN_MARKET } T_{m} \times M C_{i j m t}=\alpha_{1} \text { THIN MARKET } T_{m}+\alpha_{2} \text { THIN MARKET } m \text { MVVP }+\chi_{j}+\theta^{\prime} \mathbf{X}_{\mathbf{i}}+\kappa_{i j m t} .
$$

The idea of this estimation approach is to use the wage-loss actually suffered by occupation switchers as a predictor of the (unobserved) expected wage-loss stayers would have suffered in the case of switching. A potential point of criticism is that switchers and stayers differ in unobservable characteristics and that the realized wage-loss of a switcher might therefore be systematically different from the (unobserved) expected wage-loss of an observationally equivalent stayer. However, note that - apart from the usual demographic controls - both the first- and second-stage include occupation fixed effects. The assumption I make is therefore weaker: I assume that the differential wage-loss of switchers is a good predictor of the differential (expected) wage-loss of stayers.

In order for THIN $M A R K E T_{m} \times S V P_{j}$ to be a valid instrument it needs to be relevant, exogenous, and fulfill the exclusion restriction. An instrument is relevant if it has sufficient explanatory power for the explanatory variable, that is, if $\operatorname{corr}\left(T H I N \_M A R K E T_{m} \times S V P_{j}, T_{H I N} M A R K E T_{m} \times M C_{i j m t}\right)$ is not only marginally different

\footnotetext{
${ }^{18}$ See also Angrist and Krueger (1995), Inoue and Solon (2010), and Chapter 4.3 in Angrist and Pischke (2008).

${ }^{19}$ See Ozer-Balli and Sorensen (2010) for a discussion on how to use instrumental variables in linear regressions that include interaction effects. For example, Broner et al. (2013) is another article that uses IV and interaction effects.
} 
from zero. If this is not the case IV estimates are unlikely to be informative. This condition is testable and - as shown below - indeed holds in my data. The instrument is also arguably exogenous because $S V P_{j}$ is a pre-determined variable.

The exclusion restriction holds if, conditional on the control variables, THIN $M A R K E T_{m} \times S V P_{j}$ is uncorrelated with any other determinants of unemployment duration. The instrument THIN MARKET $m \times S V P_{j}$ must affect the unemployment duration of a workers only through the interaction THIN MARKET $m \times M C_{i j m t}$. In particular, one might argue that in a thick labor market there might be more opportunities for workers trained in highly specific tasks, leading to relatively shorter unemployment spells. However, I argue that this is unlikely given the evidence reported in Section 5.1.3: the fact that I find evidence of long spells for occupation stayers but not for occupation switchers strongly suggests that the long spells indeed result from skilled workers trying to evade switching occupations and not from simple differences in the matching technology.

\subsubsection{Results}

Table 7 presents two-sample two stage least squares estimates of the effect of mobility cost on unemployment duration. The associated first-stage estimates on the sample of occupation switchers are shown in Table 11 in the appendix. Columns (1) to (4) show results when market thickness is measured as the size of the local labor force. As before, all specifications include the usual demographic controls, occupation fixed effects, state fixed effects, and controls for plant closing. In column (2) I also allow for state-specific time trends. In the first two specifications the coefficient on the interaction is positive and significant at the $5 \%$ level. ${ }^{20}$ As reported in Table 11 in the appendix, for both specifications the first-stage is relatively strong with an F-statistic on the instrument of about 13, well above the threshold of 10 suggested by Staiger and Stock (1997). This indicates that weak instruments should not be an important concern.

As for the reduced form estimates, I compute a differential unemployment spell to make it easier to put magnitudes into perspective. According to results in column (1), if a displaced worker facing a 10\% mobility cost would be located in the thin Bakersfield, CA labor market instead of the thick labor market of the Washington metropolitan area, his unemployment spell would increase by $30 \% .{ }^{21}$ In levels, this corresponds to about 2.5 weeks.

In column (3) I include MSA fixed effects. While the coefficient of interest is less precisely estimated and not significantly different from zero, its magnitude is only slightly smaller compared to columns (1) and (2). In column (4) I restrict the sample to workers displaced due to plant closing only. The coefficient of interest

\footnotetext{
${ }^{20}$ Standard errors are corrected for the fact that in the second-stage regression (10) the interaction THIN MARKET ${ }_{m} \times M C_{i j m t}$ is estimated rather than known. I use the adjustment proposed by Inoue and Solon (2010) for a two-sample two-stage least squares (TS2SLS) setting.

${ }^{21} \exp (0.1 \times 0.5 \times 5.235)-1=29.9 \%$
} 
Table 7: Instrumental Variable Estimates

\begin{tabular}{|c|c|c|c|c|c|c|c|c|c|}
\hline & (1) & (2) & (3) & (4) & (5) & (6) & (7) & (8) & (9) \\
\hline$\left(1-\mathrm{SIZE}_{m}\right) \times \mathrm{MC}_{i j m t}$ & $\begin{array}{l}5.235^{* *} \\
(2.419)\end{array}$ & $\begin{array}{l}5.785^{* *} \\
(2.575)\end{array}$ & $\begin{array}{c}4.354 \\
(2.860)\end{array}$ & $\begin{array}{l}6.726^{*} \\
(3.642)\end{array}$ & & & & & \\
\hline$\left(1-\right.$ DIVERSITY $\left._{m}\right) \times \mathrm{MC}_{i j m t}$ & & & & & $\begin{array}{l}4.286^{* *} \\
(1.769)\end{array}$ & $\begin{array}{l}4.876^{* *} \\
(2.025)\end{array}$ & $\begin{array}{l}4.459^{*} \\
(2.282)\end{array}$ & $\begin{array}{l}7.833^{* *} \\
(3.133)\end{array}$ & $\begin{array}{l}5.754^{*} \\
(3.183)\end{array}$ \\
\hline Observations & 1,604 & 1,604 & 1,604 & 533 & 1,604 & 1,604 & 1,604 & 1,024 & 1,024 \\
\hline R-squared & 0.369 & 0.388 & 0.485 & 0.519 & 0.369 & 0.388 & 0.487 & 0.392 & 0.508 \\
\hline Diff unem spell & 0.299 & 0.335 & 0.243 & 0.400 & 0.239 & 0.276 & 0.250 & 0.479 & 0.333 \\
\hline Diff unem spell (weeks) & 2.358 & 2.590 & 1.793 & 2.121 & 1.886 & 2.126 & 1.817 & 3.998 & 2.627 \\
\hline Occupation fixed effect & yes & yes & yes & yes & yes & yes & yes & yes & yes \\
\hline State fixed effect & yes & yes & yes & yes & yes & yes & yes & yes & yes \\
\hline State time trend & no & yes & yes & yes & no & yes & yes & yes & yes \\
\hline MSA fixed effect & no & no & yes & no & no & no & yes & no & yes \\
\hline \multicolumn{10}{|l|}{ Sample } \\
\hline Plant closing only & no & no & no & yes & no & no & no & no & no \\
\hline Occs. in many inds. only & no & no & no & no & no & no & no & yes & yes \\
\hline
\end{tabular}

Notes: The regressions are two-sample two-stage least squares (TS2SLS) estimates of equation (10). The dependent variable is the length of the unemployment spell $U N E M_{i j m t}$, measured as the natural logarithm of 1 plus the weeks of unemployment: $\log \left(1+w e e k s_{i j t}\right)$. In columns (1) to (4), I operationalize market thickness using the size of the local labor force. In use size in logs in columns (1) to (4) and the empirical cumulative distribution function in columns (5) to (8). The differential unemployment spell reports the differential impact of a 10\% mobility cost on the unemployment duration of a worker when located in thick vs. thin local labor market (75th vs. 25th percentile). The associated first-stage estimates are shown in Table 11. All regressions include year-of-displacement dummies, four education dummies (dropout, high-school, some college, college or more), a female dummy, a non-black dummy, potential experience (quadratic), tenure on the pre-displacement job (cubic), and controls that capture whether displacement was due to plant closing. Only the sub-sample of displaced workers who report not to have changed occupations after displacement, whose current job was the first job after displacement, who were not noticed in advance of their displacement, and who did not move after displacement is used for estimation. In column (4) the sample is further restricted to workers who report to have been displaced due to plant closing. In columns (9) and (10) occupations present in only few industries are excluded. Standard errors clustered at the occupation level and corrected as proposed by Inoue and Solon (2010) are reported in parenthesis. ${ }^{* * *}, * *$, and ${ }^{*}$ indicate significance at the $1 \%, 5 \%$, and $10 \%$ levels.

becomes stronger but some power is lost in the first-stage due to the small sample. In spite of the reduced precision the coefficient is significant at the $10 \%$ level. $^{22}$

Columns (5) to (9) report results using the measure of industrial diversity. Estimates in columns (5) to (7) are slightly smaller compared to columns (1) to (3) where the size of the local labor market was used. However, similar to the reduced form results, the size of the estimates increases substantially once occupations spanning only few industries are excluded from the sample.

\footnotetext{
${ }^{22}$ I do not show results for the sample restricted to plant closing only including MSA fixed effects since here the first-stage is weak, see column (5) in Table 11 in the appendix.
} 


\section{Macroeconomic Implications}

\subsection{Unemployment}

In this section I explore the effect of wait unemployment on the aggregate unemployment rate in the U.S. labor market. One should think of the U.S. labor market as an agglomeration of many small submarkets or islands for specific human capital instead of a single market where one type of homogeneous labor is exchanged. In the presence of reallocation shocks, it can happen that firms are urgently looking to hire workers on one island while there is an excess of unemployed and a lack of vacancies on another. When moving across islands is costless, such a situation would not be sustainable as workers will move out of occupations that are facing slack demand. This reshuffling would continue until no dispersion across markets is left.

In the last section I showed, however, that workers actually do face substantial mobility cost when moving from one submarket to another because they invested in specific human capital. Worker mobility is therefore limited, resulting in a sustained dispersion of labor market conditions across submarkets. This dispersion in turn increases aggregate unemployment because the job finding probability is concave in the labor market "tightness," the ratio of vacancies to unemployed. Worker mobility costs can therefore give raise to aggregate unemployment as they reduce arbitrage possibilities of workers. Schematically, the mechanism can be summarized as follows:

$$
\begin{aligned}
\uparrow \text { human capital specificity } & \Longrightarrow \uparrow \text { workers face mobility cost } \Longrightarrow \downarrow \text { worker mobility } \\
& \Longrightarrow \uparrow \text { dispersion in tightness } \Longrightarrow \uparrow \text { aggregate unemployment }
\end{aligned}
$$

In this section I use a back-of-the-envelope calculation to quantify how much lower aggregate unemployment would be if all human capital would be perfectly transferable across occupations and workers would therefore not face any mobility cost. Based on my estimates of regression (6), the dispersion of labor market conditions across submarkets as a consequence of mobility cost can be expressed as

$$
\widehat{U N E M_{j m t}}=U N E M_{j m t}-U N E M_{j m t}^{S V P_{j}=0}=\widehat{\gamma_{2}} T H I N \_M A R K E T_{m} \times S V P_{j} .
$$

$U N E M_{j m t}^{S V P=0}$ is the expected (log) unemployment duration of an individual trained in occupation $j$ and residing in local labor market $m$ under the counterfactual scenario of completely transferable human capital $\left(S V P_{j}=0\right)$. As shown in Herz and van Rens (2015), the counterfactual (aggregate) job finding probability that would prevail 
Table 8: Counterfactual Aggregate Unemployment

\begin{tabular}{|c|c|c|c|c|c|c|c|}
\hline & (1) & (2) & (3) & $(4)$ & (5) & (6) & $(7)$ \\
\hline \multirow[b]{2}{*}{ Concavity } & \multicolumn{3}{|c|}{$1985-2011$} & \multicolumn{4}{|c|}{ Ratio } \\
\hline & Unem & Unem (cf) & Ratio & $1985-1990$ & $2005-2011$ & low conctr & high conctr \\
\hline$\mu=0.6$ & 0.060 & 0.055 & 0.911 & 0.911 & 0.917 & 0.998 & 0.814 \\
\hline$\mu=0.7$ & 0.060 & 0.053 & 0.874 & 0.872 & 0.883 & 0.996 & 0.749 \\
\hline$\mu=0.8$ & 0.060 & 0.050 & 0.820 & 0.814 & 0.834 & 0.994 & 0.670 \\
\hline$\mu=0.9$ & 0.060 & 0.045 & 0.742 & 0.730 & 0.763 & 0.986 & 0.574 \\
\hline
\end{tabular}

Notes: Columns (1) to (3) report the average actual U.S. unemployment rate, the counterfactual unemployment rate, and the ratio between the two for the period 1985-2011. Columns (4) to (7) show the same ratio for different sub-samples: for the periods 1985-1990 and 2005-2011 in columns (4) and (5), and for labor markets with very low and high industry concentration (1st and 5th quintile) in columns (6) and (7) (again for the period 1985-2011). All counterfactuals depend on the assumed concavity of the matching function $\mu$.

in local labor market $m$ at time $t^{23}$ can then be expressed as ${ }^{24}$

$$
\frac{P_{m t}^{c f}}{P_{m t}}=\mathbb{E}\left[\left(1+\widehat{\widehat{U N E}} M_{j m t}\right)^{\frac{1}{1-\mu}}\right]^{1-\mu}
$$

where $U \widehat{\widehat{U N E}} M_{j m t}$ is demeaned for each local labor market $m$ at time $t$ and $\mu$ is the concavity of the matching function. The counterfactual unemployment rate is then approximately given by $u_{t}^{c f} \approx u_{t} \frac{P_{t}}{P_{t}^{c f}}$ where $\frac{P_{t}^{c f}}{P_{t}}$ is a population-weighted average of $\frac{P_{m t}^{c f}}{P_{m t}}$ and $u_{t}$ is the observed unemployment rate. ${ }^{25}$

Results for the United States based on CPS basic monthly data are documented in Table 8. It is apparent that wait unemployment is an important driving force of aggregate unemployment. However, the estimates are sensitive to the assumed concavity of the matching function $\mu$. When $\mu=0.6$ as in Mortensen and Nagypál (2007), only about 8.9\% (1-0.911) of total unemployment between 1985 and 2011 can be attributed to wait unemployment. A higher (but still realistic) concavity of $\mu=0.8$ increases this share substantially to about $18 \%$. Columns (4) and (5) show that the importance of wait unemployment increased slightly over time. This is a pure composition effect that is driven by an increasing share of workers with highly specific training in the labor fore (see Figure 2).

Columns (6) and (7) document that there is also substantial variation across local labor markets: assuming again that $\mu=0.6$, I find that in thick labor markets (1st quintile) wait unemployment contributes less than

\footnotetext{
${ }^{23}$ In principle, the regression framework in this paper does not allow "wait unemployment" to vary over time. However, note that aggregate unemployment due to wait unemployment can nevertheless vary over time for compositional reasons (e.g., an increasing share of workers with highly specific training).

${ }^{24}$ I make the standard assumption that the unemployment duration follows a geometric distribution with the success probability given by the job finding probability $P_{j m t}$. The expected length of an unemployment spell is therefore given by $U N E M_{j m t}=\frac{1}{P_{j m t}}$. Taking $\operatorname{logs}$, this implies $\log \left(U N E M_{j m t}\right)=-\log \left(P_{j m t}\right)$ and $\widehat{U N E} M_{j m t}=-\widehat{P}_{j m t}$.

${ }^{25}$ This follows since in steady state unemployment can be expressed as a function of the job finding and separation probability, $u_{t}=\frac{\lambda_{t}}{\lambda_{t}+P_{t}}$.
} 


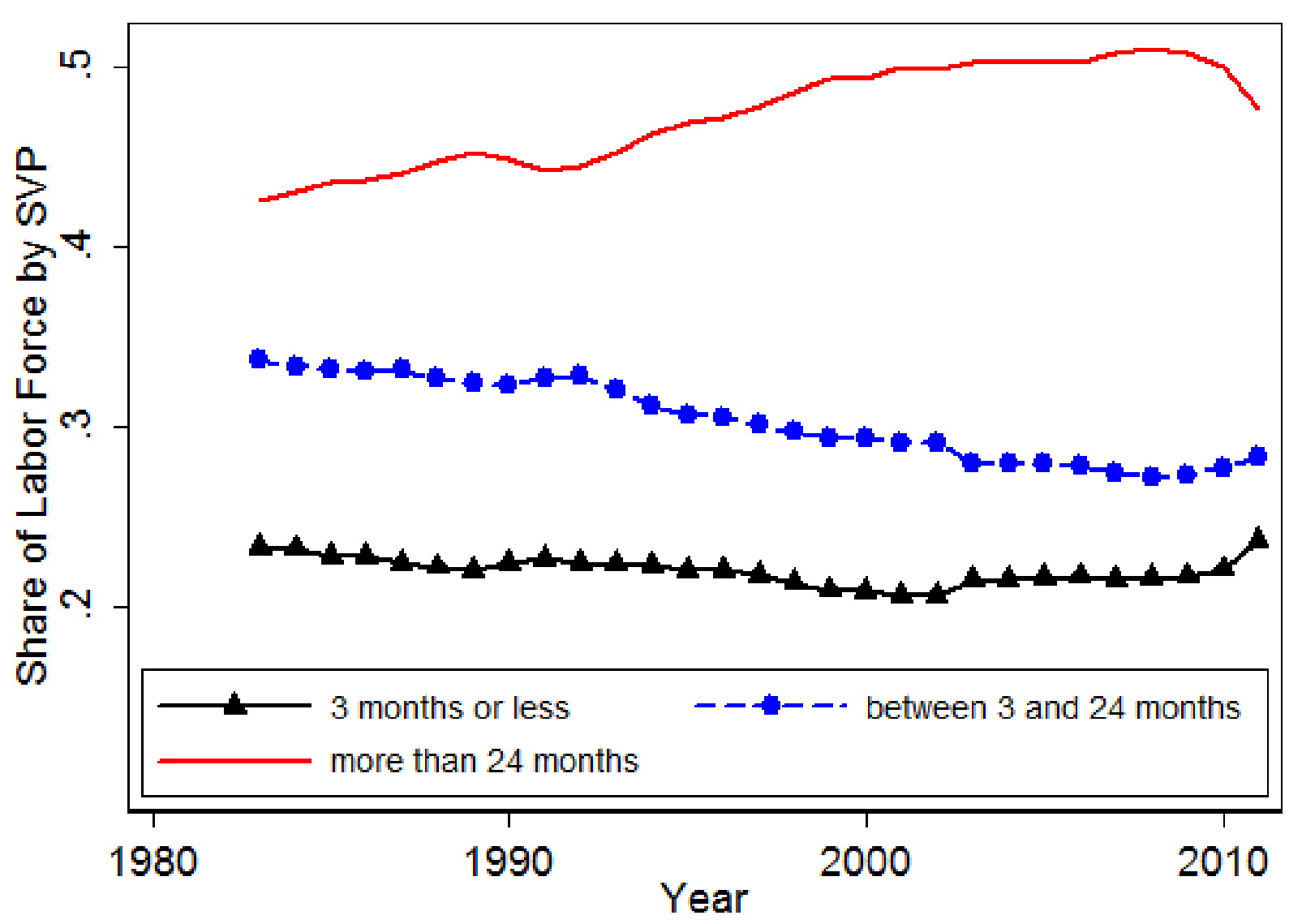

Figure 2: The evolution of the labor force shares by specific vocational preparation (SVP) based on CPS basic monthly data are shown. When a worker is employed (or is unemployed but was last employed) in a given occupation, I assume that he is endowed with the specific skills required by that occupation according to the Dictionary of Occupational Titles as described in Section 2.2. The solid line shows the share of the labor force with occupation-specific training of more than 24 months. The lines with triangles and circles show the shares with 3 months or less and with 3 to 24 months of occupationspecific training.

$1 \%$ to unemployment, while in thin labor markets (5th quintile) this figure is about $19 \%$. This finding also highlights that the effects for overall unemployment shown here should be seen as lower-bound estimates because non-metropolitan areas are not identified in the CPS-DWS and therefore neglected in the estimates presented here.

\subsection{Optimal Unemployment Insurance}

The results documented in this paper are also relevant for the ongoing debate regarding optimal unemployment insurance that especially since the Great Recession of 2008 attracts a lot of attention. It has been long understood that unemployment insurance has the potential to affect the quality of post-displacement job matches. For example, in a classic paper Marimon and Zilibotti (1999) provide a framework where extended unemployment 
benefits "provide a 'search subsidy' for giving unemployed time to find, not just a job, but the right job." More generous benefits can therefore increase worker productivity growth by preventing a "mismatch of talents" at the cost of extended spells.

While most empirical studies find that longer benefit duration leads to extended unemployment spells, the empirical evidence regarding increased post-unemployment job match quality is mixed. For example, in recent research Card et al. (2007) and Van Ours and Vodopivec (2008) find no positive effect of longer benefit duration on re-employment wages (a proxy for match quality) while Caliendo et al. (2013) document a small positive effect. $^{26}$

In light of the findings presented in this paper, one potential reason for this mixed evidence is that the effects of longer benefit duration are likely to be heterogeneous. More generous benefits should disproportionally affect the post-unemployment outcomes of workers endowed with specific vocational preparation residing thin labor markets whereas the effect on workers residing in thick markets and on workers with only general training should be small.

My findings also have implications for the design of an optimal unemployment insurance system. One objective of an optimal system should be to support workers to find a suitable post-unemployment job that allows them to make optimal use of their human capital endownment. According to my results, this would entail giving more generous benefits to workers with highly specific training residing thin labor markets. Although in most countries benefits are linked to pre-displacement earnings - and therefore increasing in SVP - I am not aware of a case where benefits depend on the characteristics of the local labor market. ${ }^{27}$ While out of the scope of the present paper, further investigating the implications of wait unemployment for the design of an optimal unemployment insurance system is an interesting avenue for future research.

\section{Conclusions}

In this paper I showed empirical evidence that wait unemployment is an important source of unemployment in the United States. Labor market skills are not perfectly transferable across jobs. In order not to experience a wage-loss, a displaced worker therefore has an incentive to wait and find a job that is as similar to his old job as possible. I empirically assessed this trade-off between waiting and suffering a wage-loss by using a difference-in-differences approach in the spirit of Rajan and Zingales (1998). I used two different sources of variation. Firstly, I exploited that the specificity of the human capital a worker invested in varies by occupation. I showed that the more specific a worker's human capital, the higher the potential wage-loss he is facing when

\footnotetext{
${ }^{26}$ For a survey article, I refer the reader to Tatsiramos and Van Ours (2014).

${ }^{27}$ For an overview of cross-country difference in unemployment insurance rules see, for example, Table 2 in Tatsiramos and Van Ours (2014).
} 
not finding reemployment in a similar job. Secondly, I exploited variation across local labor markets. In a thick labor market it will be relatively easy to find a job that matches a worker's skill-set, even when he is highly specialized; the mobility cost that goes along with switching to a different job is therefore less likely to be binding.

I constructed the following test. Using the CPS Displaced Worker Supplement, I looked at the sample of displaced workers who managed to find a job in the same occupation they worked in before. I then compared the unemployment spells of more and less specialized workers in thick and thin local labor markets. I found that in thin labor markets more specialized workers were unemployed for a longer time relative to the less specialized workers. There was no such difference observable in thick markets. Moreover, using a differencein-difference-in-differences approach I showed that this effect only exists for occupation stayers but not for switchers. I also documented that workers' occupation switching behavior is in line with wait unemployment.

I then pushed the analysis further and used a worker's specific vocational preparation as an instrument in a (two-sample) two-stage least squares (TS2SLS) regression to obtain direct estimates of how the (expected) wage-loss upon switching occupations affects unemployment duration. According to my estimates, even small mobility costs can lead to substantially extended unemployment spells.

Finally, I documented that my results have important macroeconomic implications. Using a "back-of-theenvelope" calculation, I found that between $9 \%$ and $18 \%$ of total unemployment in the United States is due to wait unemployment. Moreover, I argued that wait unemployment potentially has important implications for the design of an optimal unemployment insurance system. 


\section{References}

Abraham, Katharine G. and Henry S. Farber, "Job Duration, Seniority, and Earnings," The American Economic Review, 1987, 77 (3), 278-297.

Alesina, Alberto, Reza Baqir, and William Easterly, "Public Goods and Ethnic Divisions," The Quarterly Journal of Economics, 1999, 114 (4), 1243-1284.

Altonji, Joseph G. and Robert A. Shakotko, “Do Wages Rise with Job Seniority?," The Review of Economic Studies, 1987, 54 (3), 437-459.

Alvarez, Fernando and Robert Shimer, "Unions and Unemployment," Unpublished Manuscript, University of Chicago, 2008.

_ and _ , "Search and Rest Unemployment," Econometrica, 2011, 79 (1), 75-122.

Angrist, Joshua D. and Alan B. Krueger, "The Effect of Age at School Entry on Educational Attainment: An Application of Instrumental Variables with Moments from Two Samples," Journal of the American Statistical Association, 1992, 87 (418), 328-336.

_ and _ , "Split-Sample Instrumental Variables Estimates of the Return to Schooling," Journal of Business $\mathcal{E}$ Economic Statistics, 1995, 13 (2), 225-235.

_ and Jörn-Steffen Pischke, Mostly Harmless Econometrics: An Empiricist's Companion, Princeton University Press, 2008.

Autor, David H., David Dorn, and Gordon H. Hanson, “The China Syndrome: Local Labor Market Effects of Import Competition in the United States," American Economic Review, 2013, 103 (6), 2121-68.

Barnichon, Regis and Andrew Figura, "What drives movements in the unemployment rate? A decomposition of the Beveridge curve," 2011.

Bleakley, Hoyt and Jeffrey Lin, "Thick-market effects and churning in the labor market: Evidence from US cities," Journal of Urban Economics, 2012, 72 (2), 87-103.

Broner, Fernando, Paula Bustos, and Vasco M. Carvalho, "Sources of Comparative Advantage in Polluting Industries," Working Paper 18337, National Bureau of Economic Research 2013.

Caliendo, Marco, Konstantinos Tatsiramos, and Arne Uhlendorff, "Benefit Duration, Unemployment Duration and Job Match Quality: A Regression-Discontinuity Approach," Journal of Applied Econometrics, 2013, 28 (4), 604-627. 
Cameron, A. Colin and Pravin K. Trivedi, Microeconometrics Using Stata, Revised Edition, Stata Press, 2010.

Card, David, "Immigrant Inflows, Native Outflows, and the Local Labor Market Impacts of Higher Immigration," Journal of Labor Economics, 2001, 19 (1), 22-64.

_ , Raj Chetty, and Andrea Weber, "Cash-on-Hand and Competing Models of Intertemporal Behavior: New Evidence from the Labor Market*," The Quarterly Journal of Economics, 2007, 122 (4), 1511.

Carrington, William J., “Wage Losses for Displaced Workers: Is It Really the Firm That Matters?," The Journal of Human Resources, 1993, 28 (3), 435-462.

Dorn, David, "Essays on Inequality, Spatial Interaction, and the Demand for Skills." PhD dissertation, University of St. Gallen 2009.

Duan, Naihua, "Smearing estimate: a nonparametric retransformation method," Journal of the American Statistical Association, 1983, 78 (383), 605-610.

Easterly, William and Ross Levine, “Africa's Growth Tragedy: Policies and Ethnic Divisions," The Quarterly Journal of Economics, 1997, 112 (4), 1203-1250.

Farber, Henry S., John Haltiwanger, and Katharine G. Abraham, "The Changing Face of Job Loss in the United States, 1981-1995," Brookings Papers on Economic Activity. Microeconomics, 1997, 1997, 55-142.

_ , Robert Hall, and John Pencavel, "The Incidence and Costs of Job Loss: 1982-91," Brookings Papers on Economic Activity. Microeconomics, 1993, 1993 (1), 73-132.

Gan, Li and Qinghua Zhang, "The thick market effect on local unemployment rate fluctuations," Journal of Econometrics, 2006, 133 (1), 127-152.

Gibbons, Robert and Lawrence F. Katz, "Layoffs and Lemons," Journal of Labor Economics, 1991, 9 (4), 351-380.

Gouge, Randall and Ian King, "A Competitive Theory of Employment Dynamics," The Review of Economic Studies, January 1997, 64 (1), 1-122.

Gould, Eric D., Bruce A. Weinberg, and David B. Mustard, “Crime Rates and Local Labor Market Opportunities in the United States: 1979-1997," Review of Economics and Statistics, February 2002, 84 (1), 45-61.

Hamilton, James D., "A Neoclassical Model of Unemployment and the Business Cycle," Journal of Political Economy, 1988, 96 (3), 593-617. 
Harris, John R. and Michael P. Todaro, "Migration, Unemployment and Development: A Two-Sector Analysis," The American Economic Review, 1970, 60 (1), 126-142.

Helsley, Robert W. and William C. Strange, "Matching and agglomeration economies in a system of cities," Regional Science and Urban Economics, 1990, 20 (2), 189-212.

Herz, Benedikt and Thijs van Rens, “Accounting for Mismatch Unemployment," June 2015.

Inoue, Atsushi and Gary Solon, "Two-Sample Instrumental Variables Estimators," Review of Economics and Statistics, May 2010, 92 (3), 557-561.

Jovanovic, Boyan, “Work, Rest, and Search: Unemployment, Turnover, and the Cycle," Journal of Labor Economics, 1987, 5 (2), 131-148.

Kambourov, Gueorgui and Iourii Manovskii, "Occupational Specificity of Human Capital,", International Economic Review, 2009, 50 (1), 63-115.

King, Ian P., "A Natural Rate Model of Frictional and Long-Term Unemployment," The Canadian Journal of Economics / Revue canadienne d'Economique, 1990, 23 (3), 523-545.

Kletzer, Lori G., "Job Displacement," The Journal of Economic Perspectives, 1998, 12 (1), 115-136.

Kocherlakota, Narayana, “Economic Recovery and Balance Sheet Normalization,” June 2010.

Lilien, David M., "Sectoral Shifts and Cyclical Unemployment," Journal of Political Economy, 1982, 90 (4), 777-793.

Lucas Jr., Robert E. and Edward C. Prescott, "Equilibrium search and unemployment," Journal of Economic Theory, February 1974, 7 (2), 188-209.

Marimon, Ramon and Fabrizio Zilibotti, “Unemployment vs. mismatch of talents: reconsidering unemployment benefits," The Economic Journal, 1999, 109 (455), 266-291.

Mauro, Paolo, “Corruption and Growth," The Quarterly Journal of Economics, January 1995, 110 (3), 681-712.

Mazzolari, Francesca and Giuseppe Ragusa, "Spillovers from High-Skill Consumption to Low-Skill Labor Markets," Review of Economics and Statistics, 2011, 95 (1), 74-86.

Meyer, Peter Benjamin and Anastasiya M. Osborne, "Proposed Category System for 1960-2000 Census Occupations," Working Paper 383, U.S. Bureau of Labor Statistics September 2005. 
Miguel, Edward and Mary Kay Gugerty, "Ethnic diversity, social sanctions, and public goods in Kenya," Journal of Public Economics, December 2005, 89 (11-12), 2325-2368.

Moretti, Enrico, "Chapter 14 - Local Labor Markets*," in David Card and Orley Ashenfelter, eds., Handbook of Labor Economics, Vol. 4, Part B of Handbook of Labor Economics, Elsevier, 2011, pp. 1237 - 1313.

Mortensen, Dale T. and Éva Nagypál, "More on unemployment and vacancy fluctuations," Review of Economic Dynamics, July 2007, 10 (3), 327-347.

Murphy, Kevin M. and Robert H. Topel, “The evolution of unemployment in the United States: 1968-1985," NBER macroeconomics annual, 1987, 2, 11-58.

Neal, Derek, “Industry-Specific Human Capital: Evidence from Displaced Workers," Journal of Labor Economics, $1995,13(4), 653-677$.

Neumann, George R and Robert H Topel, “Employment risk, diversification, and unemployment,” The Quarterly Journal of Economics, 1991, pp. 1341-1365.

Ozer-Balli, Hatice and Bent E. Sorensen, "Interaction Effects in Econometrics," SSRN Scholarly Paper ID 1641004, Social Science Research Network, Rochester, NY July 2010.

Parent, Daniel, "Industry-Specific Capital and the Wage Profile: Evidence from the National Longitudinal Survey of Youth and the Panel Study of Income Dynamics," Journal of Labor Economics, 2000, 18 (2), 306-323.

Rajan, Raghuram G. and Luigi Zingales, "Financial Dependence and Growth," The American Economic Review, $1998,88(3), 559-586$.

Rodriguez-Planas, Nuria, "Playing Hard to Get: Theory and Evidence on Layoffs, Recalls, and Unemployment," Research in Labor Economics, 2013, 38, 211-258.

Ruggles, Steven, T. Alexander, Katie Genadek, Ronald Goeken, M. Schroeder, and Matthew Sobek, "Integrated Public Use Microdata Series (IPUMS): Version 5.0 [Machine-readable database]," University of Minnesota, Minneapolis, available at http://usa. ipums. org/usa, 2010.

Sahin, Aysegul, Joseph Song, Giorgio Topa, and Giovanni L. Violante, "Mismatch Unemployment," American Economic Review, 2014, 104 (11), 3529-64.

Shimer, Robert, “Mismatch,” The American Economic Review, 2007, 97 (4), 1074-1101.

Simon, Curtis J, "Frictional unemployment and the role of industrial diversity," The Quarterly Journal of Economics, 1988, pp. 715-728. 
Staiger, Douglas and James H. Stock, “Instrumental Variables Regression with Weak Instruments," Econometrica, May 1997, 65 (3), 557.

Summers, Lawrence H., Katharine G. Abraham, and Michael L. Wachter, "Why Is the Unemployment Rate So Very High near Full Employment?," Brookings Papers on Economic Activity, 1986, 1986 (2), 339-396.

Tatsiramos, Konstantinos and Jan C. Van Ours, "Labor market effects of unemployment insurance design," Journal of Economic Surveys, 2014, 28 (2), 284-311.

Tolbert, C. M. and M. Sizer, “U.S. Commuting Zones and Labor Market Areas: A 1990 Update," September 1996.

Tolbert, Charles M. and Molly Sizer Killian, “Labor Market Areas for the United States.,” January 1987.

Topel, Robert, "Specific capital and unemployment: Measuring the costs and consequences of job loss," Carnegie-Rochester Conference Series on Public Policy, 1990, 33, 181-214.

_ , "Specific Capital, Mobility, and Wages: Wages Rise with Job Seniority," Journal of Political Economy, 1991, 99 (1), 145-176.

Topel, Robert H., “Local Labor Markets,” Journal of Political Economy, 1986, 94 (3), S111-S143.

U. S. Department of Labor, Dictionary of Occupational Titles: Revised Fourth Edition 1991.

Van Ours, Jan C. and Milan Vodopivec, “Does reducing unemployment insurance generosity reduce job match quality?," Journal of Public Economics, 2008, 92 (3), 684-695.

Wheeler, Christopher H, "Local market scale and the pattern of job changes among young men," Regional Science and Urban Economics, 2008, 38 (2), 101-118. 


\section{A. Appendix}

\section{A.1. Model}

This stylized model demonstrates that for workers with specific human capital the probability to find a job that matches their skill endowment is higher in thick labor markets. Workers with highly specific human capital located in thin local labor markets are therefore especially susceptible to wait unemployment. I firstly operationalize the thickness of a labor market as the size of the market, that is, as the the number of unemployed and vacancies. I then extend the model and motivate industrial diversity as an alternative measure (see also Simon (1988) and Neumann and Topel (1991)).

Consider a stylized model with heterogeneous workers and vacancies similar to Helsley and Strange (1990) and Gan and Zhang (2006). There are $U$ unemployed workers who are looking for a vacancy in a given local labor market. Workers have heterogeneous skill endowments represented by addresses $y$ that are independently and uniformly distributed over the unit circle $[0,1)$.

Similarly, there are $V$ vacancies in the local labor market. Vacancies differ in their skill requirements represented by an address on the unit circle $x$. Like in the model by Gan and Zhang (2006), all $V$ vacancies are evenly spaced around the unit circle. The location of the 1 st vacancy is at the address $b \in[0,1)$. The $j+1$ th job is located at point $b+j / V$. If $b+j / V>1$, the location of $j+1$ th vacancy becomes $b+j / V-1$. I assume $b$ to be a random variable uniformly distributed over $[0,1)$.

Each vacancy can be matched to only one worker. The production of a filled vacancy depends on how well the skill requirement of the vacancy $x$ matches the skill endowment of the worker $y$. If $|x-y| \leq \delta$ with $0<\delta<\frac{1}{2 V}$ then the match is productive and delivers high output; the worker is remunerated by wage $w$. On the other hand, if $|x-y|>\delta$ then the worker's skill endowment and the skill requirements of the job are too far apart and the match has low productivity. In this case, the worker receives a wage $\bar{w}<w$.

Workers are aware of their own skill endowment and therefore know their location $y$ on the unit circle. They are also informed about total number of vacancies $V$ in the local labor market. However, ex-ante workers do not have information about the skill requirements of the vacancies, i.e., about the positions of vacancies on the unit circle determined by the realization of the random variable $b$. I follow Gan and Zhang (2006) and assume from now on that $U=V \equiv N$. In the following I refer to $N$ as market size.

A worker either chooses to stay and to search for a vacancy that matches his skill endowment $y$ or he decides to switch and to take on a generic job that pays $\bar{w}$. The worker's decision is based on the comparison between the expected payoff of earning a high wage $w$ at the risk of not finding a vacancy at all versus guaranteed employment at a low wage $\bar{w}$. The likelihood that a worker's skill endowment is similar enough to the skill requirement of a vacancy on the unit circle to produce a match that generates high output is given by $\frac{2 \delta}{1 / N}$. 
The expected number of other unemployed workers matching the same vacancy is given by $2 \delta \kappa(N-1)$ where $\kappa \in(0,1]$ is there share of workers who choose stay. Since a vacancy can only be matched to one worker, the ex-ante probability to fill a vacancy that matches the skill endowment of a given worker is therefore given by $p(N)=\frac{2 \delta}{1 / N} \frac{1}{1+2 \delta(\kappa(N-1))}=\frac{N}{\kappa(N-1)+\frac{1}{2 \delta}} \cdot p(N)$ is increasing in market size $N$.

For a worker, the expected payoff of searching is $p(N) w$ while the payoff of taking a generic job is $\bar{w}$. If $p(N) w \geq \bar{w}$, then all workers are going to stay and search for a vacancy that matches their skill endowment. On the other hand, if $p(N) w<\bar{w}$, some workers will switch and take on generic jobs. The lower the share of workers $\kappa$ who stay, the lower is the probability that more than one worker compete for one high quality match and the higher therefore $p(N)$; in equilibrium, workers decide to switch such that $p^{*}(N) w=\bar{w}$.

This model delivers two simple insights. Firstly, workers located in thick markets are less likely to engage in wait unemployment since the likelihood to find a productive match $p(N)$ is high. Secondly, the workers most susceptible to wait unemployment are workers who, firstly, are located in thin labor markets, and secondly, face high potential wage losses $\frac{w}{w}$, that is, workers endowed with highly specific human capital.

The trade-off that workers (in thin markets) face between waiting and wage-loss derived from this model is simplistic: workers are willing to trade-off a $1 \%$ increase in the probability of being unemployment for a $1 \%$ increase in wage. However, the stylized (static) model is not rich enough capture other factors that matter for this trade-off in the real world. To give a few examples: The discount factor matters since the higher future payoffs are discounted, the less willing are workers to stay wait unemployed. The level of unemployment benefits is decisive: the higher would lead to a higher willingness to go trough spells of wait unemployment since they make the state of being unemployed less "painful." As highlighted by Mortensen and Nagypál (2007), the utility of leisure and the value of non-market activity have similar effects. Also, the benefits of having a job with a higher wage are the greater the lower the probability to lose that job again. The lower the separation probability, the higher is therefore the willingness to wait for better employment. ${ }^{28}$ Finally, there might be a stigma attached to going through long spells of unemployment which would decrease the willingness to go trough extended spells of wait unemployment.

\section{A.1.1. Industrial Diversity}

I now sketch and extension of the model to motivate the use of industrial diversity instead of market size as an alternative way to operationalize market thickness. There are I industries. Industries differ in the occupations they employ. This can be incorporated in the model by assuming that a given industry $i$ posts all its vacancies

\footnotetext{
${ }^{28}$ Summers et al. (1986) mentions this mechanism: "Investing in waiting for a high-wage job makes much more sense for mature married men, who as a group have a very low employment turnover rate, than for other demographic groups that have much higher turnover rates."
} 
within a segment $\left[c_{i}, c i+\lambda\right]$ of the unit circle where $c_{i} \in[0,1)$ and $0<\lambda<1$. (If $c_{i}+\lambda \geq 1$, the segment is given by $\left.\left[c_{i}, c i+\lambda-1\right].\right)$ I assume for simplicity that $\lambda$ is the same for all industries. It is important to note that industries can overlap in their skill requirements and vacancies that are potentially posted within a segment of the unit circle can therefore come from various industries.

In a market with high industrial diversity, employment - and therefore vacancy posting - is evenly spread across industries. I model this by assuming that, while the total number of vacancies is still $V$, only a share $0<\gamma \leq 1$ of the $I$ industries posts vacancies in a given market; the bigger $\gamma$, the more diverse is the market. The worker is aware of the parameter $\gamma$, however, ex-ante he does not know whether a given industry $i$ is going to post vacancies or not. In a very non-diverse market with one active industry at a time, for example, vacancies will be posted only to a share $\lambda$ of the unit circle. In general, the probability that a skill segment $\epsilon \in(0,1-\lambda)$ is not covered by any of the (active) industries and therefore no vacancy will be posted for these skill requirements is given by $(1-\lambda-\epsilon)^{I \gamma}$ and therefore decreasing in industrial diversity $\gamma$.

In order to make this idea tractable in the model, I deviate from the assumption that $V$ vacancies are evenly spaced around the unit circle. Instead, depending on the industrial diversity of the local market, vacancies are spread only around a share $D \in(0,1]$ of the unit circle that is increasing in industrial diversity. $D=1$ refers to a market with maximal diversity. As before, the location of the 1st vacancy is at the address $b \in[0,1)$ where $b$ is a random variable. However, the $j+1$ th job is now located at point $b+D(j / V)$. If $b+D(j / V)>1$, the location of $j+1$ th job becomes $b+D(j / V)-1$.

As before, a worker is aware of his own skill endowment and therefore of his position on the unit circle and of the industrial diversity $D$ of the local market. Moreover, as before he is not aware of the positions of the vacancies, that is, of the realization of the random variable $b$.

Conditional on being located in the share $D$ of the unit circle, $\frac{2 \delta}{D / N}$ is the likelihood that the worker's skill endowment is similar enough to the skill requirement of a vacancy if $\frac{2 \delta}{D / N}<1$. This conditional likelihood is decreasing in diversity $D$ : since all $V$ vacancies are posted in that segment, the lower $D$, the higher the concentration of vacancies in that segment. However, for $\frac{2 \delta}{D / N} \geq 1$ the probability is 1 since a worker cannot apply to more than one vacancy and a vacancy can only match to one worker. At this point, the effect that only workers who are located in the share $D$ of the unit circle can find high quality matches dominates.

If $\frac{2 \delta}{D / N}<1$, the expected number of other workers matching the same vacancy is given by $2 \delta \kappa(N-1)$ where, as above, $\kappa$ denotes the share of stayers. If $\frac{2 \delta}{D / N}>1$, this number is given by $\frac{D}{N} \kappa(N-1)$. The ex-ante probability to fill a vacancy that matches the skill endowment of a given worker is therefore given by 


$$
p(D)= \begin{cases}D \frac{1}{1+\frac{D}{N} \kappa(N-1)} & \text { if } \frac{2 \delta}{D / N} \geq 1 \\ D \frac{2 \delta}{D / N} \frac{1}{1+2 \delta \kappa(N-1)} & \text { if } \frac{2 \delta}{D / N}<1 .\end{cases}
$$

$p(D)$ is (weakly) increasing in industrial diversity $D$. The qualitative implications of the model therefore remain the same, no matter whether market thickness is operationalized as market size or industrial diversity. 


\section{A.2. Data Appendix}

\section{A.2.1. Displaced Workers Supplement}

The sample consists of workers between 20 and 67 years of age who lost a job in the private sector between 1983 and 2012 due to plant closing, insufficient work, or because their shift was abolished. Note that this does not only exclude quits but also - according to the CPS Interviewer Memorandum - it explicitly excludes events where workers are fired for "poor work performance, disciplinary problems, or any other reason that is specific to that individual alone" (Farber et al., 1993). That is, as a first approximation the displacement can be seen as being an exogenous shock. I further restrict the sample to those who lost a full-time job and are currently full-time re-employed. This is necessary because I only observe hours worked for the current job, but not for the pre-displacement job. Weekly earnings is therefore the only wage measure available for both the pre- and post-displacement job. All earnings are deflated by the GDP deflator with base year 2005 that I obtained from the Bureau of Economic Analysis. Following earlier papers in the literature, I drop workers who report pre- or post-displacement earnings below $100 \$$ per week

The CPS-DWS only asks follow-up questions about at most one lost job. If an individual lost more than one job within the three year period, he is only asked about the job he held the longest. To guarantee that the "initial unemployment spell" is from the spell immediately preceding the current job, I exclude multiple job losers included in the sample. ${ }^{29}$ Moreover, note that due to an error conducted by the surveyors the unemployment spell is not reported in the 1994 CPS-DWS. Descriptive statistics are shown in Table 9.

\section{Moved after displacement}

The CPS-DWS also provides information on whether displaced workers moved after displacement. In specification where I make use of local labor market information I also the restrict the sample to workers who report not to have moved.

\section{Advance notice}

In most specifications I further restrict the sample to workers who report not having received an advance notice of displacement. Not making this restriction might lead to misleading results, in particular when the dependent variable is the unemployment duration reported by a worker. The reason is that an advance notice of displacement gives workers the possibility to undertake on-the-job-search which is not captured by the reported unemployment duration. Moreover, it seems that the efficiency of this potential on-the-job-search systematically varies with other co-variates such as education and specific vocational preparation. It would

\footnotetext{
${ }^{29}$ For example, compare Rodriguez-Planas (2013).
} 
therefore not be sufficient to account for this effect by simply including an advance notice indicator variable as a control.

\section{Plant closing}

As mentioned above, according to the CPS-DWS definitions the displacement of a worker should be an exogenous event. However, it might still be that de-facto workers with (unobserved) low ability are more likely to be displaced. This would result in a selection problem. If, for example, low ability workers are also systematically endowed with less specific vocational training they might also be less willing to engage in wait unemployment. The consequence would be an omitted variable problem that potentially leads to downward-biased estimates.

To address this issue I take into account whether a worker reports having been displaced because of plant closing. When a plant is closed down, all workers are displaced by definition; the firm does not have any discretion with respect to whom to lay off. This greatly reduces concerns about a potential selection problem (Gibbons and Katz, 1991). All regressions therefore include dummy variables that indicate whether a worker was displaced to plant closing. In some regressions I go further and restrict the sample to workers who report having been displaced because of plant closing. While restricted sample is therefore arguably preferable to the baseline sample it comes at the cost of a substantially reduced sample size.

\section{Recall expectations}

Another potential issue is that, although the CPS-DWS is restricted to workers who permanently lost a job, some workers might expect to be recalled to their old job. Since the 1994 survey workers are asked "Do you expect to be recalled to that job [that you lost]?" I find that in the pooled sample only $3.1 \%$ of displaced workers answered "yes" to this question. Temporary layoffs are therefore very unlikely to affect my results.

Moreover, a displaced worker cannot be recalled to a job that disappeared due to the closing down of a plant. Any remaining effect should therefore be captured by the dummy variables that control for plant closing in all regressions.

\section{A.2.2. Specific Vocational Preparation}

The revised fourth edition of the Dictionary of Occupational Titles (DOT) published by the U.S. Department of Labor in 1991 evaluates 12741 occupations along several dimensions, such as physical and cognitive demands. In particular, the DOT reports the "specific vocational preparation" (SVP) required to work in a given occupation. SVP is defined as 
Specific Vocational Preparation is defined as the amount of lapsed time required by a typical worker to learn the techniques, acquire the information, and develop the facility needed for average performance in a specific job-worker situation.

This training may be acquired in a school, work, military, institutional, or vocational environment. It does not include the orientation time required of a fully qualified worker to become accustomed to the special conditions of any new job. Specific vocational training includes: vocational education, apprenticeship training, in-plant training, on-the-job training, and essential experience in other jobs. Specific vocational training includes training given in any of the following circumstances:

a. Vocational education (high school; commercial or shop training; technical school; art school; and that part of college training which is organized around a specific vocational objective);

b. Apprenticeship training (for apprenticeable jobs only);

c. In-plant training (organized classroom study provided by an employer);

d. On-the-job training (serving as learner or trainee on the job under the instruction of a qualified worker);

e. Essential experience in other jobs (serving in less responsible jobs which lead to the higher grade job or serving in other jobs which qualify).

The variable is categorical and ranges from 1 to 9 where 9 refers to very high specificity. In order to make occupation codes comparable with the CPS data, I first use a crosswalk provided by the National Crosswalk Service Center $^{30}$ to match each of the 12741 DOT occupations to one of 469 U.S. Census 1990 occupations. I then apply the conversion table from Meyer and Osborne (2005) to match each U.S. Census occupation into one of 368 consistent occupation codes. The SVP of an occupation is then defined as the median SVP of all matched DOT occupations. ${ }^{31}$

I generate a cardinal variable by calculating the empirical cumulative distribution function of SVP using occupational employment data from the 1995 CPS. ${ }^{32}$ The transformed variable can then be interpreted as the share of the employed workforce in 1995 that works in occupations with equal or smaller required specific vocational preparation. The original variable and its transformation are described in Table 1.

\footnotetext{
${ }^{30} \mathrm{http}: / /$ www.xwalkcenter.org

${ }^{31}$ Optimally, one would use the employment-weighted mean of the matched DOT occupations. However, DOT occupation categories are very narrowly defined such that reliable employment figures are not available. Since there is few variation of the SVP measure within the DOT occupations that are matched to the same consistent occupation code the results of applying weights would be negligible in any case.

${ }^{32}$ Results in the paper are robust to the choice of the base year.
} 


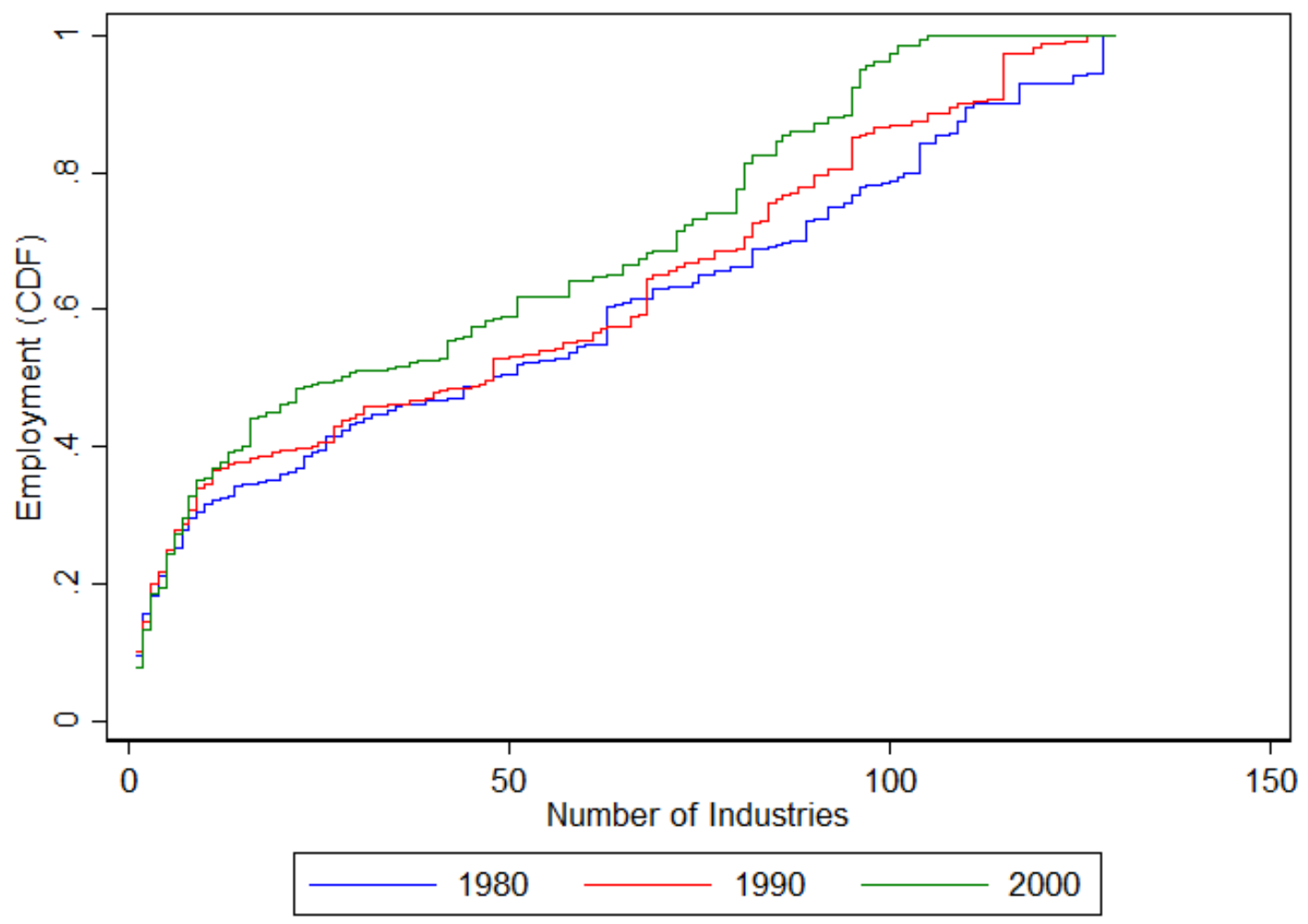

Figure 3: The figure shows the cumulative distribution function of employment when occupations are ranked according to the number of industries they are found in. For example, according to the 1990 Census, the median employee works in an occupation that can be found in 48 industries. Data for the 1980, 1990, and 2000 U.S. Census is shown.

\section{A.3. Occupational Employment Across Industries}

In this section I document that, while occupations exist that are concentrated in few industries, most occupations can be found in many industries. Based on data from the U.S. Census, I calculate the industrial employment shares for each occupation. In order to obtain a robust estimate of the number of industries an occupation is active in, I calculate the (minimum) number of industries that account for $90 \%$ of an occupation's employment. As before, I use time-consistent occupation and industry codes based on the 1990 classification. When occupations are ranked according to this industry count, the median worker in the 1990s U.S. Census is employed in an occupation that spans 48 industries, see Figure 3. The total number of industries is 236. As can be seen in Figure 3 the industry-span is lower according to the 2000 U.S. Census. The reason is most likely that substantial changes in the occupation and industry classification system were implemented in the 2000 Census. $^{33}$

\footnotetext{
${ }^{33}$ https://www.census.gov/people/io/files/techpaper2000.pdf
} 
Table 9: CPS Displaced Worker Supplement, Descriptive Statistics

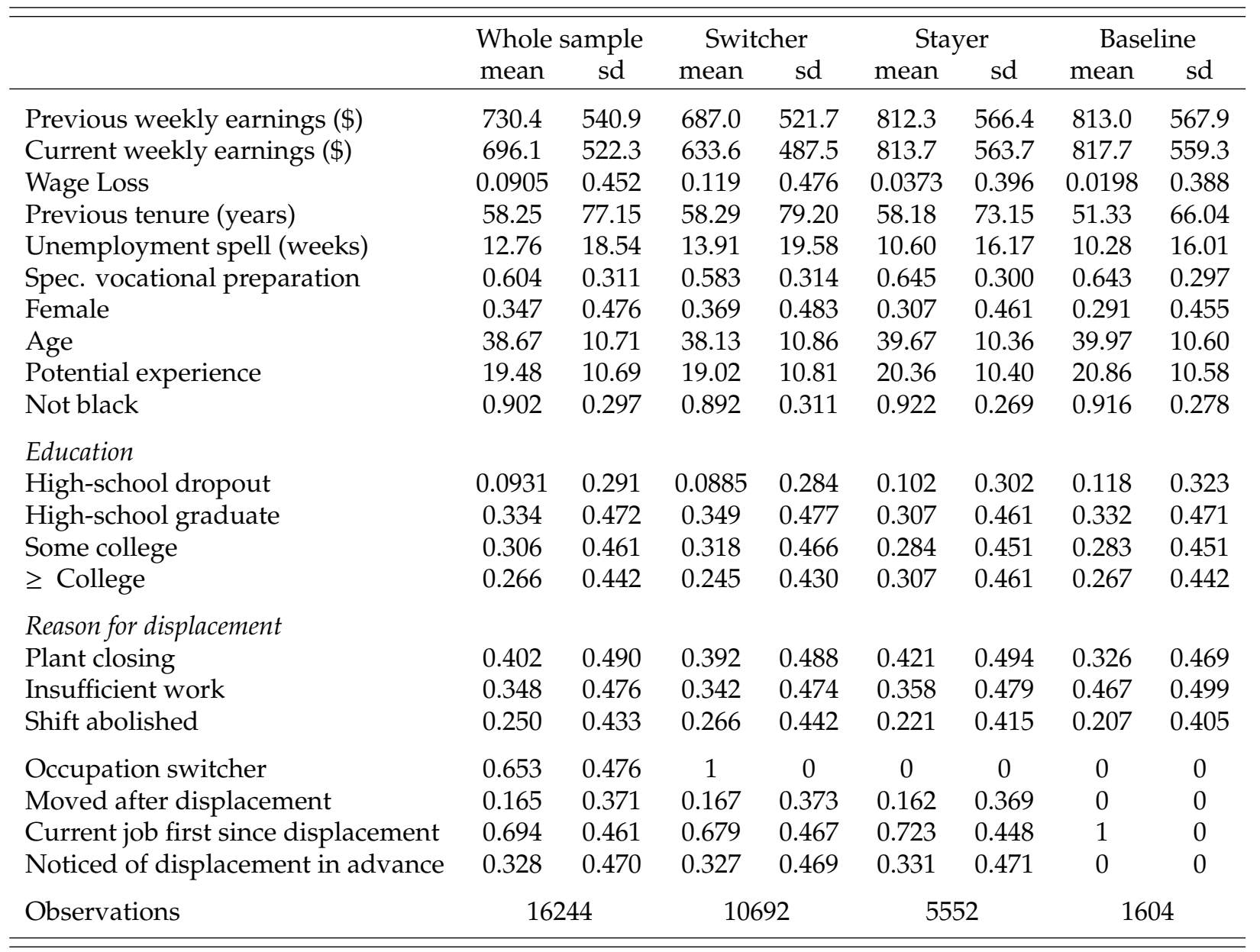

Notes: Descriptive statistics of the CPS Displaced Worker Supplement are shown. Reported numbers have to be interpreted as shares unless mentioned otherwise. Wage-loss is defined as the difference in log real weekly earnings (2005 \$). Whole sample refers to the CPS-DWS when both occupation stayers and switchers are included in the sample. As described in detail in Section 2, the sample is restricted to workers between 20 and 67 years of age who lost a job in the private sector due to plant closing, insufficient work, or because their shift was abolished between 1983 and 2012. Moreover, they lost a full-time job and are currently full-time re-employed. In the columns Switcher (Stayer) the sample is further restricted to workers who report that their current job is in a different (same) occupation than their pre-displacement occupation. Baseline refers to the sample that I use for estimation in Tables 3, 4, 7, and 12. In this case the sample is again restricted to occupation stayers. Further, it is restricted to (1) workers who were not noticed in advance of their displacement, (2) who report that the current job is the first job after displacement, (3) who report not to have moved after displacement, and (4) who live in a metropolitan statistical area (MSA) that is identified in the CPS-DWS. 
Table 10: Geographic Mobility

\begin{tabular}{lcccccc}
\hline \hline & $(1)$ & $(2)$ & $(3)$ & $(4)$ & $(5)$ & $(6)$ \\
\hline MOVED $_{i j m t}$ & $-0.0725^{* *}$ & $-0.0761^{* * *}$ & $-0.0680^{* *}$ & 0.0477 & 0.0394 & 0.0547 \\
MOVED $_{i j m t i} \times \mathrm{SVP}_{j}$ & $(0.0285)$ & $(0.0286)$ & $(0.0277)$ & $(0.0602)$ & $(0.0627)$ & $(0.0686)$ \\
& & & & $-0.179^{* *}$ & $-0.172^{* *}$ & $-0.181^{* *}$ \\
& & & & $(0.0843)$ & $(0.0841)$ & $(0.0889)$ \\
\hline Observations & 5,032 & 5,032 & 5,032 & 5,032 & 5,032 & 5,032 \\
R-squared & 0.234 & 0.252 & 0.297 & 0.235 & 0.253 & 0.299 \\
Occupation fixed effect & yes & yes & yes & yes & yes & yes \\
State fixed effect & no & yes & yes & yes & yes & yes \\
State time trend & no & yes & yes & no & yes & no \\
MSA fixed effects & no & no & yes & no & no & yes \\
\hline \hline
\end{tabular}

Notes: The regressions are least squares estimates of regression equation (9). The dependent variable is 0 if the pre- and post-displacement occupation of a displaced worker is the same and 1 if it is different. All regressions include year-of-displacement dummies, four education dummies (dropout, high-school, some college, college or more), a female dummy, a non-black dummy, potential experience (quadratic), tenure on the pre-displacement job (cubic), and controls that capture whether displacement was due to plant closing. For displaced workers who report to have moved, state- and MSA fixed effects refer to the location at the time of the interview. The regression also controls for the length of the completed unemployment spell. The sample contains both workers who have and who have not changed occupations after displacement. The sample is restricted to workers whose current job was the first job after displacement and who were not noticed in advance of their displacement. Standard errors clustered at the occupation level are reported in parenthesis. ${ }^{* * *}, * *$, and * indicate significance at the $1 \%, 5 \%$, and $10 \%$ levels.

Table 11: First-Stage Estimates

\begin{tabular}{|c|c|c|c|c|c|c|c|c|c|c|}
\hline & (1) & $(2)$ & (3) & $(4)$ & (5) & (6) & (7) & (8) & (9) & $(10)$ \\
\hline$\left(1-\mathrm{SIZE}_{m}\right) \times \mathrm{SVP}_{j}$ & $\begin{array}{l}0.189^{* * * *} \\
(0.0514)\end{array}$ & $\begin{array}{l}0.196^{* * *} \\
(0.0516)\end{array}$ & $\begin{array}{l}0.202^{* * *} \\
(0.0547)\end{array}$ & $\begin{array}{l}0.231^{* * *} \\
(0.0775)\end{array}$ & $\begin{array}{l}0.186^{* *} \\
(0.0831)\end{array}$ & & & & & \\
\hline$\left(1-\right.$ DIVERSITY $\left._{m}\right) \times \operatorname{SVP}_{j}$ & & & & & & $\begin{array}{l}0.245^{* * *} \\
(0.0616)\end{array}$ & $\begin{array}{l}0.248^{* * *} \\
(0.0626)\end{array}$ & $\begin{array}{l}0.259^{* * *} \\
(0.0661)\end{array}$ & $\begin{array}{l}0.231^{* * *} \\
(0.0750)\end{array}$ & $\begin{array}{l}0.256^{* * * *} \\
(0.0794)\end{array}$ \\
\hline Observations & 3,192 & 3,192 & 3,192 & 987 & 987 & 3,192 & 3,192 & 3,192 & 2,345 & 2,345 \\
\hline R-squared & 0.230 & 0.239 & 0.316 & 0.402 & 0.532 & 0.263 & 0.272 & 0.336 & 0.257 & 0.331 \\
\hline F-statistic excl. instr. & 13.57 & 14.44 & 13.62 & 8.892 & 5.024 & 15.87 & 15.70 & 15.34 & 9.492 & 10.42 \\
\hline Occupation fixed effect & yes & yes & yes & yes & yes & yes & yes & yes & yes & yes \\
\hline State fixed effect & yes & yes & yes & yes & yes & yes & yes & yes & yes & yes \\
\hline State time trend & no & yes & yes & yes & yes & no & yes & yes & yes & yes \\
\hline MSA fixed effect & no & no & yes & no & yes & no & no & yes & no & yes \\
\hline \multicolumn{11}{|l|}{ Sample } \\
\hline Plant closing only & no & no & no & yes & yes & no & no & no & no & no \\
\hline Occs. in many inds. only & no & no & no & no & no & no & no & no & yes & yes \\
\hline
\end{tabular}

Notes: The regressions are least squares estimates of equation (11) when market thickness is operationalized as size of the local labor force. The associated second-stage regression is equation (10). The dependent variable is the interaction $-\log \left(\mathrm{SIZE}_{m}\right) \times \mathrm{MC}_{i j m t}$ in columns (1)-(4) and (1- SIZE $\left.\mathrm{E}_{m}\right) \times \mathrm{MC}_{i j m t}$ in columns (5)-(8). All regressions include year-of-displacement dummies, four education dummies (dropout, high-school, some college, college or more), a female dummy, a non-black dummy, potential experience (quadratic), tenure on the pre-displacement job (cubic), and controls that capture whether displacement was due to plant closing. Only the subsample of displaced workers who report to have changed occupations after displacement, whose current job was the first job after displacement, who were not noticed in advance of their displacement, and who did not move after displacement is used for estimation. In columns (4) and (5) the sample is further restricted to workers who report to have been displaced due to plant closing. In columns (9) and (10) occupations present in only few industries are excluded. Standard errors clustered at the occupation level are reported in parenthesis. ${ }^{* * *}, * *$, and ${ }^{*}$ indicate significance at the $1 \%, 5 \%$, and $10 \%$ levels. 
Table 12: Reduced Form Estimates: Tobit

\begin{tabular}{|c|c|c|c|c|c|c|c|c|c|c|}
\hline & (1) & $(2)$ & (3) & (4) & (5) & (6) & (7) & (8) & (9) & (10) \\
\hline$\left(1-\mathrm{SIZE}_{m}\right) \times \mathrm{SVP}_{j}$ & $\begin{array}{c}1.132^{* * *} \\
(0.424)\end{array}$ & $\begin{array}{c}1.302^{* * *} \\
(0.423)\end{array}$ & $\begin{array}{l}0.997^{* *} \\
(0.449)\end{array}$ & $\begin{array}{l}1.728^{* *} \\
(0.806)\end{array}$ & $\begin{array}{l}1.696^{*} \\
(0.885)\end{array}$ & & & & & \\
\hline$\left(1-\right.$ DIVERSITY $\left._{m}\right) \times \operatorname{SVP}_{j}$ & & & & & & $\begin{array}{c}1.164^{* * *} \\
(0.401)\end{array}$ & $\begin{array}{c}1.348^{* * *} \\
(0.400)\end{array}$ & $\begin{array}{c}1.263^{* * *} \\
(0.412)\end{array}$ & $\begin{array}{c}2.003^{* * *} \\
(0.493)\end{array}$ & $\begin{array}{c}1.648^{* * *} \\
(0.508)\end{array}$ \\
\hline Observations & 1,604 & 1,604 & 1,604 & 533 & 533 & 1,604 & 1,604 & 1,604 & 1,019 & 1,019 \\
\hline Left-censored & 299 & 299 & 299 & 133 & 133 & 299 & 299 & 299 & 175 & 175 \\
\hline Occupation fixed effect & yes & yes & yes & yes & yes & yes & yes & yes & yes & yes \\
\hline State fixed effect & yes & yes & yes & yes & yes & yes & yes & yes & yes & yes \\
\hline State time trend & no & yes & yes & yes & yes & no & yes & yes & yes & yes \\
\hline MSA fixed effect & no & no & yes & no & yes & no & no & yes & no & yes \\
\hline \multicolumn{11}{|l|}{ Sample } \\
\hline Plant closing only & no & no & no & yes & yes & no & no & no & no & no \\
\hline Occs. in many inds. only & no & no & no & no & no & no & no & no & yes & yes \\
\hline
\end{tabular}

Notes: The regressions are Tobit estimates of equation (6). I operationalize market thickness as size of the local labor force in columns (1) to (3) and as industrial diversity in columns (4) to (6). All regressions include year-of-displacement dummies, four education dummies (dropout, high-school, some college, college or more), a female dummy, a non-black dummy, potential experience (quadratic), tenure on the pre-displacement job (cubic), and controls that capture whether displacement was due to plant closing. Only the sub-sample of displaced workers who report not to have changed occupations after displacement, whose current job was the first job after displacement, who were not noticed in advance of their displacement, and who did not move after displacement is used for estimation. In columns (4) and (5) the sample is further restricted to workers who report to have been displaced due to plant closing. In columns (9) and (10) occupations present in only few industries are excluded. ${ }^{* * *}, * *$, and $*$ indicate significance at the $1 \%, 5 \%$, and $10 \%$ levels. 